Board of Governors of the Federal Reserve System

International Finance Discussion Papers

Number 1125

November 2014

\title{
How Public Information Affects Asymmetrically Informed Lenders: \\ Evidence from a Credit Registry Reform
}

M. Ali Choudhary and Anil K. Jain

NOTE: International Finance Discussion Papers are preliminary materials circulated to stimulate discussion and critical comment. References to International Finance Discussion Papers (other than an acknowledgment that the writer has had access to unpublished material) should be cleared with the author or authors. Recent IFDPs are available on the Web at www.federalreserve.gov/pubs/ifdp/. This paper can be downloaded without charge from Social Science Research Network electronic library at www.ssrn.com. 


\title{
HOW PUBLIC INFORMATION AFFECTS ASYMMETRICALLY INFORMED LENDERS: EVIDENCE FROM A CREDIT REGISTRY REFORM
}

\author{
M. ALI CHOUDHARY* AND ANIL K. JAIN ${ }^{\dagger}$
}

\begin{abstract}
We exploit exogenous variation in the amount of public information available to banks about a firm to empirically evaluate the importance of adverse selection in the credit market. A 2006 reform introduced by the State Bank of Pakistan (SBP) reduced the amount of public information available to Pakistani banks about a firm's creditworthiness. Prior to 2006, the SBP published credit information not only about the firm in question but also (aggregate) credit information about the firm's group (where the group was defined as the set of all firms that shared one or more director with the firm in question). After the reform, the SBP stopped providing the aggregate group-level information. We propose a model with differentially informed banks and adverse selection, which generates predictions on how this reform is expected to affect a bank's willingness to lend. The model predicts that adverse selection leads less informed banks to reduce lending compared to more informed banks. We construct a measure for the amount of information each lender has about a firm's group using the set of firm-bank lending pairs prior to the reform. We empirically show those banks with private information about a firm lent relatively more to that firm than other, less-informed banks following the reform. Remarkably, this reduction in lending by less informed banks is true even for banks that had a pre-existing relationship with the firm, suggesting that the strength of prior relationships does not eliminate the problem of imperfect information.
\end{abstract}

Keywords: Information, Credit registries, Financial Intermediation

JEL codes: G14, 016

Date: November 2014.

* State Bank of Pakistan. Email: ali.choudhary@sbp.org.pk and Federal Reserve Board of Governors ${ }^{\dagger}$ Email: anil.k.jain@frb.gov. We wish to thank Abhijit Banerjee, Emily Breza, Rebecca Dizon-Ross, Esther Duflo, Ben Feigenberg, Robert Gibbons, Benjamin Golub, Conrad Miller, Ben Olken, Jennifer Peck, Adam Sacarny, Annalisa Scognamiglio, Ashish Shenoy, Tavneet Suri, and Robert Townsend for their amazing support on the paper. We thank banking-cluster executives of the State Bank of Pakistan for their support and candid feedback. We also would like to thank commercial bank senior executives for participating in our interviews. We also very grateful to seminar participants at North-Eastern University Development Conference (NEUDC), Fuqua Business School, Olin Business School, Haas College of Business, Bank of England, Federal Reserve Board of Governors, University of Illinois at Urbana-Champaign (UIUC) and Simon Fraser University. All mistakes are our own. The findings and conclusions in this paper are solely the responsibility of the authors and should not be interpreted as reflecting the views of the Board of Governors of the Federal Reserve System, the views of any other person associated with the Federal Reserve System or the views of the State Bank of Pakistan. 


\section{INTRODUCTION}

Credit markets are crucial to economic growth but asymmetric information may hinder their effectiveness. Jaffee and Russell [1976] and Stiglitz and Weiss [1981 theoretically show that adverse selection is a factor that can substantially constrain the effectiveness of credit markets, yet the extent to which this factor is a problem in credit markets remains largely unknown. It is possible, for example, that lenders face other binding constraints (such as those due to moral hazard) that make adverse selection less relevant.

The key empirical challenge to isolating the importance of adverse selection in the real world is that the variation in the individual observations is unlikely to be exogenous. For example, lending could drive the asymmetry of information rather than the reverse: one bank may know more about a firm than another bank simply because it has a lent to that firm in the past.

An innovative recent paper by Karlan and Zinman [2009] on adverse selection (and moral hazard) in credit markets tackles one aspect of this issue. Karlan et. al examine if exogenously lowering the interest rate changes selection of the borrower pool in ways that the lender cannot observe. While they are able to highlight borrower behavior, they are still unable to observe changes in lender behavior in the presence of information asymmetries. In particular, they are not able to demonstrate that lenders react to these changing unobservables by altering the terms they offer - since the set of contracts offered by the lenders is fixed - which is the key mechanism behind credit market failure in the theoretical literature.

The purpose of this paper is to show that banks do change their lending behavior in reaction to a change in the distribution of information about a particular firm. In particular, among a group of differentially informed lenders, we ask: What is the effect of reducing public information about a borrower's creditworthiness?

A regulatory reform by the State Bank of Pakistan (SBP) in April 2006 offers a unique opportunity to answer this question. The reform exogenously reduced the amount of public information available to lenders about a firm's creditworthiness and did so in a way that varied across firm-lender pairs. Specifically, the change limited a lender's capacity to procure information about a firm's relationships to other firms.

Until April 2006, the SBP had supplemented credit information about prospective borrowers with information about that firm's "group." This group was defined as all other firms which shared at least one director with the borrowing firm.1 But in April 2006,

${ }^{1}$ Firms within a group have complex interfirm relationships which subsequently have important economic implications. There is both theoretical and empirical evidence that interfirm relationships may be a mechanism for tax reduction (Desai and Dharmapala 2009]), tunneling (Bertrand et al. 2002]), risk 
the SBP stopped defining a firm's group and in doing so stopped providing group-specific information (see section 3.1 for more detail).

Lenders value such information about the credit of other firms in a borrower's network because assets and profits may be transferred within a group of firms - especially if one firm is in financial difficulty. For instance, when Lehman Brothers Holdings Inc. filed for bankruptcy, an unscheduled transfer of $\$ 8$ billion occurred from the European operations (Lehman Brothers International) to the US operations. 2. In all, the firm's bankruptcy led to $\$ 38$ billion in claims among the various arms of Lehman Brothers and took over three years of litigation to settle. $]^{3}$

We take advantage of the natural experiment the SBP reform generated: We use a difference-in-difference methodology to estimate the causal effect of the reduction in public information on a bank's willingness to lend In particular, we exploit variation in the impact of the policy across firm-bank pairs generated by each bank's other lending relationships. Suppose a firm borrowed from two different banks in Dec 2004. Following the reform, we predict that one bank - the informed bank - could have more information about the firm's actual liabilities, if other members of the firm's group also borrow from that bank. We then compare how the loans that the firm receives from the informed and the uninformed banks changes after the reform. In addition, we examine whether the reform affected a firm's ability to access total credit by comparing loan amounts received by firms who had informed lenders, and those who did not, before and after the policy reform.

Our main result shows that banks with private information about other firms in a firm's group lent more to that firm than other, less-informed lenders did, after the reform, both on an extensive margin (5.4 percent more likely to renew the firm's loan) and on an intensive margin (larger loans). This is the primary evidence that the reduction in public information amplified the problem of adverse selection in the credit market.

Second, those firms that borrowed from informed lenders were likely to borrow 11-14\% more than those firms who did not have access to informed lenders. In other words, both the level of credit and its source were affected.

Third, using the distribution of firm-bank pairs and the strength of interfirm relations we construct a measure for the quality of private information each bank possessed about a firm's group prior to the reform. Following the reform, those lenders with greater private

sharing (Khwaja and Mian [2005a|), the efficient working of organizations (Williamson 1975, 1981]) and internal capital markets (Stein [1997, Almeida and Wolfenzon [2006, Gopalan et al. [2007]).

2 "Outcry Grows Over Transfer of U.K. Funds by Lehman", Wall Street Journal, published September 22, 2008. http://online.wsj.com/article/SB122204286442761375.html

3 "Lehman Ends $\$ 38$ Billion Standoff"', Wall Street Journal, published October 5, 2012. http://online. wsj . com/article/SB10000872396390444223104578038234046506220.html

${ }^{4}$ For brevity, in this paper we use "bank" to denote any financial institution. 
information about a firm's group were more likely to renew a firm's loan 5 This further supports the claim that a greater information differential between lenders leads to a greater disparity in the likelihood of a loan being renewed.

Fourth, there is substantial heterogeneity in the measured effect across firms: The smaller firms in a group were the most disadvantaged from the information change. There was no effect on the largest firms in a group, which suggests either that information about these borrowers was already pervasive, or that the relative cost of procuring the information was lower.

Fifth, those firms which had negative information in their credit reports in December 2004 were the most affected by the change in information reporting. They were $18 \%$ more likely to renew their loan at an informed lender. Those firms with a poor credit history are likely to be the most risky for a bank, making public information all the more important for these firms. A firm may have overdue loans, but if the rest of the group is prompt in their repayment, it may signal a sufficiently creditworthy borrower. However, if both the firm and the group are overdue, this could signal wider systemic issues in the firm's creditworthiness.

The rest of the paper proceeds as follows: Section 2 reviews the relevant literature on credit markets, and section 3 describes the institutional background, and explains the SBP's reasoning in instituting the change in lending policy. Section 4 presents a stylized model to explain the results and shows how information asymmetries between lenders can be important. Section 5 outlines our econometric framework for analysing the importance of information asymmetries across lenders and details our results. Section 6 outlines the effects of the reform on a firm's ability to procure credit and section 7 presents a summary and concluding remarks for future research.

\section{Literature Review}

This paper's main contribution is to empirically assess the impact of adverse selection in credit markets with differentially informed lenders. There is a long theoretical literature describing how asymmetric information in credit markets causes lenders to alter what contracts they offer. Compared to an environment with full information, this can lead to the misallocation of capital (Jaffee and Russell [1976], Stiglitz and Weiss [1981, 1983], De Meza and Webb 1987]), even to the complete unraveling of the credit market Akerlof [1970]). Yet, the empirical evidence for adverse selection is relatively limited.

${ }^{5}$ Since the strength of interfirm ties vary, we can construct various measures for the quality of private information a bank may possess about a firm dependent on who the bank lends to within that firm's group, and the relative strength of those interfirm relationships. 
Karlan and Zinman's novel experiment separately identified adverse selection and moral hazard in microcredit but only found weak evidence for adverse selection effects. It is unclear if the small effects they find are due to the small loans in the microcredit sector, or because the experiment only used individuals who borrowed from the lender previously, or if adverse selection is not a key problem in lending. Ausubel [1999] uses a randomized trial which varied the contractual terms for a pre-approved credit card for 600,000 individuals. Contrary to Karlan and Zinman, Ausubel finds large effects of adverse selection in the credit card industry. To the best of our knowledge our paper is the first paper that examines adverse selection in corporate lending. Filling the gap in the literature, we examine the effects of adverse selection in a market with much larger loans and in a setting where we expect the effect of adverse selection to be very different. Additionally, we examine how lenders react to the change in a set of observable characteristics - which is the key mechanism leading to credit market failure in the theoretical literature.

The classic literature on information problems in credit markets highlights the effect of asymmetric information on symmetrically informed lenders. Recent papers examine the theoretical and empirical effect of information asymmetries across lenders. Stroebel 2013 theoretically models the interest rates a borrower receives when mortgage lenders are differentially informed about the borrower's collateral. He shows empirically that the return is higher for more informed lenders. Moreover, due to the winner's curse, less informed lenders charge higher interest rates when competing against more informed lenders.

Consistent with Stroebel's results we find the more informed lenders to be better off. Yet our environment has richer intertemporal variation that allows us to address different issues. First, our model endogenizes a firm's total borrowings and we empirically test whether the more informed lenders offer larger loan sizes than other lenders. Second, while Stroebel relies on pre-existing differences in whether the lender also built the property, we identify the effect of differential information exploiting an exogenous change in public information reporting. Third, because firms in our setting have multiple loans, we can estimate the effect of differential information across lenders for the same firm.

Public information performs three key roles in credit markets: (i) it reduces information asymmetries between the borrower and the lender, (ii) reduces information asymmetries between lenders and (iii) reduces a borrower's incentive to default. However, public information does have drawbacks. First, it may reduce a lender's incentive to procure information if the information will be later revealed by a credit registry. Second, public information may be imprecise or noisy causing excessive volatility in the observed public information (Morris and Shin 2002).

Public information is often considered a substitute for private information, or a leveler of the playing field, but this is not always true. For example, consider a scenario where 
two banks can lend to the same firm but only one bank knows the identity of all the directors of this firm. Providing a directory of director creditworthiness to both firms, would only benefit the firm who is privately informed about the firm's composition of directors. Therefore, it is possible for public information to be a complement to private information.

Hertzberg et al. 2011] empirically demonstrate how merely the prospect of publicly announcing a bank's private credit rating about a firm can lead to strategic effects by lenders, and the subsequent reduction of credit. Lenders strategically reduced lending to borrowers who they had previously labeled as a poor credit. They argue that lenders reduced lending since the public information revelation would lead to other lenders reappraising their lending terms and potentially reducing their credit lines to the borrower, causing the borrower financial stress.

Our paper is similar to Hertzberg et al. in that we analyze the effects of altering public information in an environment with multiple lenders. Since the change in public information is common to all lenders, lenders must take into account how the change in public information affects their willingness to lend and how the change affects their competitors' willingness to lend.

Although both Hertzberg et al. and our paper examine changes in public information, the form of the public information is quite different. Hertzberg et al. analyze a reform which publicly released a lender's appraisal of a firm's creditworthiness whereas in the reform that we analyze, the credit registry altered the information available about the firm's ongoing credit history. Hertzberg analyzes a reform where lenders respond to the expectation of a bad credit rating becoming public knowledge limiting the firm's capacity to procure credit; by contrast, we study a reform where the SBP removed the ongoing capacity to monitor a firm.

This paper contributes to the literature on relationship banking (Petersen and Rajan 1994, Berger and Udell 1995, Degryse and Van Cayseele 2000]). The prior literature has highlighted the potential for banking relationships to overcome the problem of information problems. Our paper emphasizes that the strength of these prior relationships does not completely eliminate the problem of imperfect information.

There is a nascent literature examining how variation in private information affects loan officers' decisions. Hertzberg et al. 2010, Cole et al. 2012, Paravisini and Schoar 2012] all examine how loan officers evaluate whether they should offer loans, and at what terms, under different information structures. This is similar to our paper's environment except the loan officers must consider not only what information they can observe, but what other information may be available to other lenders. 
Our paper examines the importance of interfirm relationships in a firm's ability to procure credit. Khwaja and Mian 2005a, 2008, Khwaja et al. 2011 show two key and related points: first, interfirm relationships allow insurance against idiosyncratic shocks; and second, politically connected firms are able to garner political favors for the entire set of related group firms. There is similar evidence in developed economies, Haselmann et al. 2013] show how social connections between banks and firms can facilitate more favorable lending terms for the firm. This paper emphasizes a mechanism for improved access to credit that is distinct from the intragroup lending channels studied in previous work. In particular, we suggest that the interfirm relationships may help firms procure loans since a lender considers the creditworthiness of both the firm and the firm's group. Therefore, being part of a group with a perfect credit history can facilitate a firm's access to credit. To our knowledge, this is the first paper that shows that information about a firm's group has implications on a firm's ability to borrow.

\section{Data And Institutional Background}

Bank lending is the primary source of formal funding in Pakistan. For instance in 2002, Pakistan's main stock exchange, the Karachi Stock Exchange, only had a market capitalization of $16 \%$ of GDP, which is much smaller than the more mature NYSE which had a market capitalization of $92 \%$ of GDP (Khwaja and Mian 2005b] $)$. The small size of public equity and debt issuance is a common feature amongst emerging stock markets. In part this is due to institutional failings, for example Khwaja and Mian 2005b show that brokers in Pakistan manipulated public stock prices through "pump and dump" schemes to earn rates of return 50-90 percentage points higher than outside investors.

The data comes from the State Bank of Pakistan's electronic Credit Information Bureau (e-CIB), which legally requires all banks and lending institutions to submit data on all borrowing firms with outstanding loan amounts greater than 500,000 Pakistani Rupees (equivalent to about $\$ 8500$ in 2004) 6 Some of the information collected by the SBP was passed back to the banks to facilitate lending. The information was provided through "credit worthiness reports." A sample report is shown in figure 20 in the Appendix.

The creditworthiness report provided information about the firm's total borrowing, overdue loans, ongoing litigation against the firm, and amounts written off in the last five years. In addition, the central bank provided information on a firm's group borrowing, that is, the total borrowing by all firms which shared a mutual director, and whether the group had any amount overdue. However, the central bank did not provide information on which firms were in the firm's group - it was solely the aggregate group's credit history.

${ }^{6}$ This limit was removed in April 2006, and all loans (regardless of size) were required to be reported to the e-CIB. 
Therefore, the individual banks would have different information about who - and who was not - in the firm's group.

Financial institutions use the credit reporting system as an initial appraisal and to monitor the ongoing creditworthiness of a firm. In an interview a former loan officer remarked: "The eCIB is used to verify credit history and monitor exposure, both during and after approval [of the loan]." Additionally, the banks' written notes on a firm's credit worthiness mention that credit reports were checked.

In April 2006, the central bank instituted new policies about the amount of information they would provide about a firm through the credit reports. Specifically, the central bank reduced the amount of information they would provide about a firm's "group." An example of the new report is shown in Figure 21 in the Appendix. The main difference between the reports is that the key terms detailing the group's outstanding loans were removed in 2006, hampering the lending institution's ability to conduct due diligence on the firm and group. A bank has limited capacity to recoup its funds on non-performing loans - emphasizing the need to conduct sufficient due diligence prior to offering a loan. In 2005, Pakistani banks recouped a mere $14.1 \%$ of the value of the loans which were classified as Non-Performing Assets (Ministry of Finance 2006]).

Further there is important information in the creditworthiness of a firm's group. The probability of any corporate loan in our dataset being overdue in December 2004 was $2.6 \%$. However, conditional on any firm in the firm's group being overdue on a loan, that firm was 6.2 percentage points more likely to be overdue on his loan. After controlling for observables such as loan size, total borrowings, bank fixed effects, those firms who had an overdue firm in their group were 6.8 percentage points more likely to be overdue on their loans than firms with perfectly creditworthy partners. This highlights the importance of understanding the creditworthiness the firm's group in assessing the creditworthiness of the firm.

This paper argues that this reduction in information had a major impact on bank lending decisions. It led banks to lend more to those firms about which they had private information.

\subsection{Why did the State Bank of Pakistan alter the information available to} lending institutions? Prior to April 2006, the State Bank of Pakistan defined a firm's group as those firms which shared a director. However, due to firms lobbying the SBP,

this definition of groups was altered, because the SBP believed that the definition of a group was too broad and not an adequate measure of control.

The following quote comes from the minutes of an interview with Mr. Inayat Hussein, head of the Banking and Regulation at the SBP — the group responsible for designing 
and implementing the prudential regulation titled "Criteria of Grouping Companies for the CIB Report," and outlines the motivations behind the change:

"The 2004 criteria of grouping for the purpose of CIB reports resulted in tying together some companies/firms/individuals, otherwise historically financially sound, with defaulters. This happened due to common directorship definition which also includes nominee directors who have little influence on the management of the firm. Hence, the SBP management decided to recognize and differentiate between those controlling shares in a group from common directors having no influence over the management of the group in question. Notwithstanding, SBP also appreciated financial institution's need to take informative decisions if complete information of allied companies is not provided in the credit worthiness reports."

These views were represented in the confidential internal minutes of a meeting of the SBP in May 2004. The State Bank's intention was to provide a new definition for groups - one which would offer a better measure of control than the previous definition. However, the SBP delegated the responsibility for constructing the group relations to the banks, stating that "the onus for correct formation of the group as per definition given in the Prudential Regulations will be on Banks" (State Bank of Pakistan, 2004 Prudential Regulation). So the banks - the main beneficiaries of receiving information about a firm's group - were the ones expected to provide the information to the SBP.

The State Bank specifically warned against reporting too large a group, stating that: "Banks are advised to be very careful while reporting the names of group entities in the CIB data. In case any party disputes the group relationship, the reporting Bank should be able to defend its position with documentary evidence" (State Bank of Pakistan, 2004 Prudential Regulation), further reducing the bank's incentive to report a firm's group to the SBP.

Ultimately, the regulation led banks to report almost no group information to the central bank. Since the SBP was no longer constructing group liabilities, and banks were not reporting group entities, banks were left to construct their own groups. Therefore, they were forced to make their own definition of groups and conduct their own due diligence. A current credit officer remarked: "With the new e-CIB system, you have do your own intel and also consider past information for firms" and in the new system "the full group information was not declared - overall I preferred the older system."

3.2. Other sources of firm information for a bank. Lenders access multiple different sources of information about a borrower prior to offering a loan. They collect information from the borrower using a standard form - the Basic Borrower Fact Sheet (BBFS), the 
firm's accounts, and some information held by the Securities and Exchange Commission of Pakistan (SECP). Lenders also consult other people in the banking industry.7 The information reported in the BBFS and SECP detail who are the firm's directors and the amount of shareholding each director holds.

Thus if a lender has a loan application from two firms, who share a mutual director, using the information from the BBFS and the SECP, the lender can determine the existence of an interfirm relationship and the strength of the relationship (as proxied via the shareholdings). Further, we suspect if a bank lent to two members of the same group, the bank would have better information about that firm's group.

3.3. Building firm links. The State Bank of Pakistan collects information on all directors of a firm that borrows from a bank. This includes the director's name, father's name, a common identifier, shareholding and home address. At the baseline of December 2004 we have details of 174,244 director relationships and 97,449 firms. ${ }^{8}$

3.4. What does the network of firms look like? Figure 1 shows the network of firm connections across the entire set of borrowing firms in Pakistan in December 2004. A connection between two firms is shown if both firms have at least one mutual director.

The most visually striking aspect of the network is the huge dense network of firm connections in the center of the figure. The largest component ${ }^{9}$ is a total of 2395 firms in December 2004 10

Figure 5 in section 8 shows what the network of firms looks like if we restrict attention to interfirm relationships where a mutual director owns at least $25 \%$ of the firm's equity. Figures 6 and 7 show the distribution of the number of connections each firm has and the distribution of component size.

\footnotetext{
${ }^{7}$ It was surprising to us that loan officers mentioned talking to other banks to learn more about a client's credit worthiness. A further way to procure knowledge of a firm's group is via the SBP, lenders can query which firms a director is part of, however, our interviews with loan officers suggest that the knowledge of this facility is not apparent.

${ }^{8}$ The e-CIB is missing the common identifier for a total of 19,473 of these director relationships and these are omitted from our sample. Since the common identifier was also used to compile which firms were in groups, our definition of which firms were in groups should not be affected.

${ }^{9} \mathrm{~A}$ component is defined as, the set of nodes such that every node within the component has either a direct or indirect connection to every other node within the component.

${ }^{10}$ It should be noted, we are only building the component of firms using the set of firms currently borrowing. Therefore, the giant component should really be seen as a underestimate of the true size of the largest component since there are possibly non-borrowing firms which would link other firms into the giant component.
} 
FiguRE 1. The network of firm connections

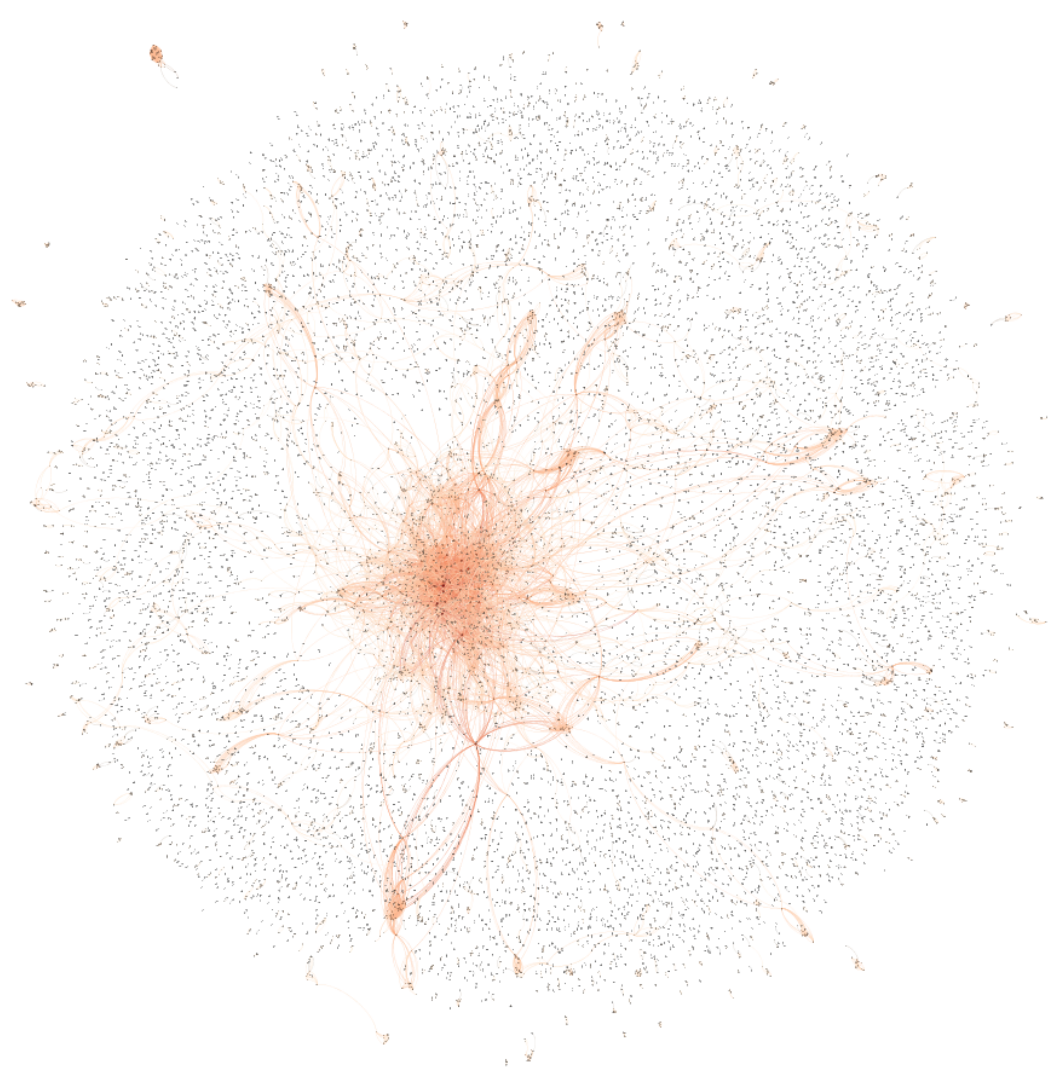

Only firms with at least one connection are shown in the graph above. The circles and edges in the picture correspond to firms and connections between firms respectively, where a connection is defined if both firms have at least one mutual director. Those firms with more connections are slightly darker and larger in the diagram.

3.5. The data. The loan level data comes from the SBP's credit registry. The data includes information on all directors for each firm and the amount of equity each director holds. Furthermore, the data set in December 2004 included data on a total of 97,449 firms. 11,395 are corporate firms and 86,053 are sole proprietorship or small firm loans. In April 2006, as part of an overhaul of the credit registry database, two separate registries were created: (1) corporate firms and (2) all consumer. The data on sole proprietor loans was moved into the consumer database and the data on corporate firms was kept within the corporate database. Simultaneously, some of the original corporate firms were placed in the consumer dataset - therefore, to maintain a consistent dataset of firms throughout the period, we use the set of firms which were ex-post defined to be corporate firms and 
maintained within the credit registry. Further, we exclude publicly listed firms due to our expectation that there should not be effected by the reform and a lack of sufficient sample size.

The SBP defined a firm's group as the set of firms with a common director in the entire borrowing data set of 97,449 firms. This paper follows the same definition of a group, using the entire database of 97,449 firms in December 2004.

The data set stretches from December 2004 to December 2008, however there are data validation concerns immediately following the regulation change. Therefore the months from April to August 2006 are dropped from the data set. The new credit registry required more information on borrowers to be uploaded by banks (for SBP's role of supervising of the banking system, not for the purposes of the credit registry ${ }^{11}$ and subsequently required banks to upload the data in a new format which led to some initial teething problems. In all our main within-firm regressions we include a bank interacted with time fixed effect, therefore, if there was any time-varying bank-specific measurement error (which was common across all the bank's loans), then this fixed effect should alleviate this concern.

In addition, one of the banks, Union Bank, was taken over in late 2006. Since data reporting was poor during the takeover, that bank is omitted from all specifications.

The paper examines "funded" loan balances. A funded loan is a credit which is backed by the bank, such that in the case of defaults, the bank must attempt to recover the loan directly from that firm or person. The bank is the residual claimant on the loan. On the other hand, non-funded loans are backed with a letter of credit or a personal guarantee - if the borrower defaults, the bank can repossess funds from the guarantor.

The majority of lending are working capital balances, which are normally renewed every 12 months. They are similar to an overdraft facility, where firms are able to borrow more or less at any stage subject to their total borrowing limit. Unfortunately, data on the borrowing limit was not collected by the SBP prior to April 2006, therefore, the paper restricts attention to the total amount borrowed in any month.

The data set details a loan to be overdue in any particular month if the loan amount was overdue for more than 90 days.

There are a total of 94 banks which offer loans to corporate firms in 2004, but the sample is restricted to banks offering at least 50 corporate loans in December 2004. This leaves a final data set of 55 banks and $96.4 \%$ of the original data.

\footnotetext{
${ }^{11}$ It is important that the extra information being collected in 2006, is solely for purpose of SBP's role of supervising the credit market since if the credit registry was displaying more information than it was in 2004 , this could potentially conflate some of the observed effects of the regulation change.
} 
The sample is restricted to both harmonize the data set and for tractability. Many of the specifications use three high dimensional fixed effects: 'firm interacted with date', 'firm interacted with bank' and 'bank interacted with date'. Therefore, by removing the very smallest banks, the computation is greatly sped up.

All variables which include nominal amounts have been discounted to December 2004 prices using the official Pakistani CPI index published by the State Bank of Pakistan.

Tables 1 and 2 present summary statistics on the entire dataset as well as showing more detailed statistics on group firms. Figures 8 and 9 show the distribution of total firm borrowings and the distribution of loan sizes for group firms.

\section{MOdEL}

The model demonstrates how lenders who are differentially informed about a firm's creditworthiness decide whom to lend to, and how much to lend, after assessing the creditworthiness of borrowing firms and what information other lenders may have.

The model aims to show how lending patterns change between informed and uninformed lenders as we alter the composition of the borrower pool, and as we alter the informational differential between lenders.

4.1. Setup. There are three players in the model; two lenders and a single firm. There are two different types of firms, a high type, $H$, and a low type, $L$, which vary in the probability of repayment. The probability of the low type is $\gamma$ and the probability of the high type is $(1-\gamma)$.

Both lenders have the same cost of capital $(\rho)$, however one of the lenders $(I)$ - the informed lender - is more informed of the firm's type than the other $(N)$ - the uninformed lender.

The firm has no outside source of funds, no collateral and limited liability. The firm is able to undertake a project such that if a firm of type $i$ invests $k$ in the project, the firm's output $Y_{i}(k)$ is:

$$
Y_{i}(k)= \begin{cases}A k & \text { with probability } \frac{X_{i}}{1+k} \\ 0 & \text { else }\end{cases}
$$

Where $X_{L}<X_{H}<1$, therefore the high type is more likely to have a successful project conditional on the amount borrowed, $k$. The project's expected output, $E\left[Y_{i}(k)\right]$ is increasing and concave in capital, so the expected return $E\left[Y_{i}(k) / k\right]$ is decreasing in capital.

For simplicity, we shall assume that the interest rate $(R)$ is exogenously fixed at a rate greater than the cost of capital $(\rho)$ and lower than the return of the project $(A)$ if successful: 


$$
\rho<R<A
$$

This is not an innocuous assumption since it stops competition over interest rates. Yet it seems empirically plausible as Khwaja and Mian [2008] demonstrate for Pakistani corporate firms and Petersen and Rajan 1994 for small business firms in the US, interest rates are not responsive to changes in lending costs or information respectively. Both papers find large effects on the amount of credit each bank is willing to offer.

To ensure there is the prospect of there being "lemons" in the model we assume:

$$
\frac{R X_{L}}{\rho}<1<\frac{R X_{H}}{\rho}
$$

Inequality (1) states the maximum expected return from the low (high) type borrower is lower (greater) than the cost of capital for the lender. Therefore inequality (1), states that if the lenders knew the firm was a low-type, it would not be profitable to offer that firm any loans.

Further, for ease of exposition in the proof 12 we assume that $\frac{R X_{L}}{\rho}>\frac{1}{2}$ and we assume that $\frac{R X_{H}}{\rho}<4$.

We assume a lender can only make non-negative loan offers, $k_{j} \geq 0$.

The firm has limited liability, no outside wealth and no collateral. Further, the firm cannot strategically default on a loan - this could be due to legal requirements or the lender can repossess the firm's output. We define a firm default at lender $i, D^{i}$, if a firm received a loan and the project was unsuccessful.

For simplicity we have assumed that both the informed lender and the uninformed lender know that there exists one lender of each type. In the context of the empirical setting this is not so clear. Banks do not know what information other banks do and do not possess.

\subsection{Timing.}

(1) Nature chooses the firm's type $X_{i}$.

(2) The informed lender observes $X_{i}$.

(3) The informed and uninformed lenders make simultaneous bids $\left(k_{j}\right)$ over how much to lend at an interest rate $R$.

(4) The firm accepts none, one, or both of the loan offers.

(5) The project is successful, or not, and payoffs are assigned.

\footnotetext{
12 These bounds on the set of parameter values are sufficient conditions which greater simplify the proofs for certain boundary cases (when the uninformed lender does not enter).
} 
Figure 2 outlines the extensive form of the game.

Figure 2. Extensive form of the game.

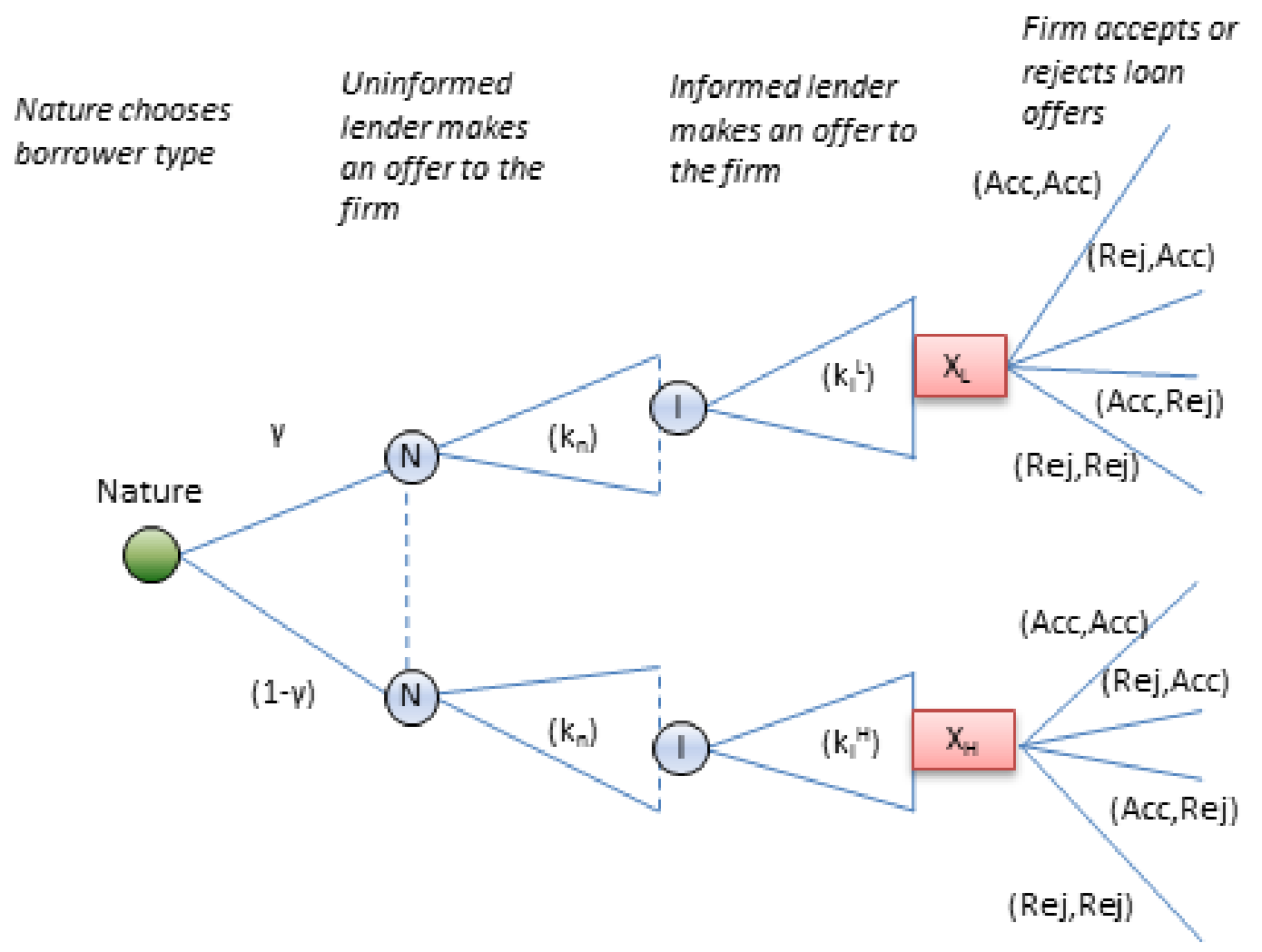

4.3. The game. We will consider the Perfect Bayesian Equilibrium of the game.

To solve for the equilibrium of the game, we will use backward induction. Firstly we solve for the contract offers the firm will accept. Second, conditional on the firm's strategy, we solve for the optimal loan offer by each of the lenders.

4.3.1. The firm's problem. The firm wants to maximise its expected utility, which takes the form:

$$
\begin{aligned}
U_{i}(k, R) & =\operatorname{Pr}(\text { success }) \times(A k-R k) \\
& =\frac{X_{i}}{1+k}(A-R) k
\end{aligned}
$$

Where $k$ is the firm's total borrowings. This specific utility function has some key advantages, which will greatly simplify the model. The firm's utility $U_{i}(k, R)$ exhibits strictly increasing returns in capital for all interest rates below the productivity parameter, $A$. 
Therefore, the firm's weakly dominant strategy will be to accept all loan offers.

4.3.2. The informed (I) lender's problem. Having solved the firm's problem, we know the firm will accept all loan offers. The informed lender's problem becomes:

$$
\begin{aligned}
\pi_{I}^{i}\left(k_{I}^{i}, k_{N}, X_{i}\right) & =\max _{k_{x}^{i}} \operatorname{Pr}(\text { success }) \times\left(k_{I}^{i}\right)-\rho k_{I}^{i} \\
& =\left[\frac{X_{i}}{1+k_{I}^{i}+k_{N}} R-\rho\right] k_{I}^{i} \\
\pi_{I}^{i}\left(k_{I}^{i}, k_{N}, X\right) & \geq 0 \\
k_{I}^{i} & \geq 0
\end{aligned}
$$

Where $k_{I}^{i}$ is the informed lender's loan offer to the firm of type $i$ and $k_{N}$ is the uninformed lender's loan offer. The informed lender's problem is to maximise the expected return from lending to a borrower (conditional on the uninformed lender's loan amount) minus the cost of lending.

Recalling the assumption that the cost of capital is greater than the maximum repayment from the low type $\left(\rho>X_{L} R\right)$. In this case, the informed lender will not lend to the low-type firm, since the expected profit from any non-zero capital offer is negative:

$$
\pi_{I}^{L}\left(k_{I}^{L}, k_{N}, X\right)<0 \quad \forall k_{I}^{L}>0
$$

Therefore, the informed lender will make the offer $k_{I}^{L}=0$ in equilibrium.

4.3.3. The uninformed (N) lender's problem.

$$
\begin{aligned}
E\left(\pi_{N}\left(k_{I}, k_{N}, X\right)\right) & =\max _{k_{N}} E_{X}\left\{\operatorname{Pr}(\text { success }) \times\left(R k_{N}\right)-\rho k_{N}\right\} \\
& =E_{X}\left\{\left[\frac{X_{i}}{1+k_{I}^{i}\left(X_{i}\right)+k_{N}} R-\rho\right] k_{N}\right\} \\
E\left(\pi\left(k_{I}, k_{N}, X\right)\right) & \geq 0 \\
k_{N} & \geq 0
\end{aligned}
$$

The uninformed lender's problem is similar to the informed lender's problem. However the uninformed lender does not observe the firm's type, so the lender must maximise over the expectation of the firm's type. It should be noted that the uninformed lender must also consider that the informed lender's loan offer will be a function of the firm's type. In particular, the uninformed lender will face more competition on the high-type firms than the low-type. 


\subsection{Equilibrium.}

Proposition 1. A Perfect Bayesian equilibrium of the game is:

$$
\begin{aligned}
\text { (informed lender) } k_{I}^{L} & =0, k_{I}^{H}=k_{I}^{H *}>0 \\
\text { (uninformed lender) } k_{N} & =k_{N}^{*} \geq 0 \\
\left(\text { firm) } s_{f}^{i}\right. & =(\text { Acc, Acc })
\end{aligned}
$$

Proof. In the appendix.

Therefore, the informed lender will always offer the null offer $k_{I}^{L}=0$ to the low-type firm. Further the informed lender, will always make a positive loan offer $\left(k_{I}^{H *}\right)$ to the high-type firm.

The uninformed lender will make an offer an offer $k_{N}^{*}$, which may be the null offer. The uninformed lender makes the null offer $k_{N}^{*}=0$ when the problem of adverse selection is sufficiently severe that the uninformed lender is unable to make positive profits when entering the market.

The firm's weakly dominant strategy is to accept all loan offers 13 ,

Proposition 2. The informed lender will lend more in expectation than the uninformed lender:

$$
\Delta k \equiv \gamma k_{I}^{L}+(1-\gamma) k_{I}^{H}-k_{N}>0
$$

Proof. In the appendix.

Proposition 2 shows that the informed lender will make larger loans on average than the uniformed lender. If the firm is a high-type, the uninformed lender competes with the informed lender on offering a loan, therefore, they split the profits from servicing the high-type firm. However, on the low-type firms, the uninformed lender is the sole provider of loans and makes a loss. Overall, the losses from the low-type firm leads the uninformed lender to make smaller loans on average.

Proposition 3. If the uninformed continues to lend, the uninformed lender will have greater rates of default than the informed lender:

$$
\Delta D \equiv E\left[D^{N}-D^{I} \mid k_{N}>0\right]>0
$$

\footnotetext{
${ }^{13}$ There is another PBE where both the informed and uninformed lender's make the null offers $k_{I}^{L}=k_{I}^{H}=$ $k_{N}=0$, and the firm rejects all loan offers. Given these strategies, no lender or firm could be better off. However, we ignore this equilibrium in our analysis, since it involves the firm playing a weakly dominated strategy.
} 
Proof. In the appendix.

The information asymmetry leads the uninformed lender to offer loans to the low-type borrowers leading to greater default rates. Combining proposition's 2 and 3 the uninformed lender lends less than the informed lender and makes worse quality loans.

The lack of public information leads to two sources of welfare loss: (1) the good borrowers can receive too much capital and (2) the low-type borrowers receive too much capital.

Proposition 4. As we reduce $X_{L}$, the expected difference between how much the informed and uniformed lender offer is increasing.

$$
\Delta \equiv(1-\gamma) k_{I}-k_{N} \text { is decreasing in } X_{L}
$$

Proof. In the appendix.

As we decrease the quality of the "lemons" in the model, the uninformed lender makes greater losses by servicing the entire market. This leads to the uninformed lender reducing her overall lending.

Since the informed lender never makes an offer to the low-type borrower, the informed lender is affected solely through the reduction in the uninformed lender's willingness to offer loans. If the uninformed lender reduces the size of her loan offer, the informed lender's optimal reaction is actually to increase her offer.

4.5. Allowing for differing quality of information. We can extend the model to allow for varying differences in information between the informed lender and the uninformed lender.

Formally, instead of the informed lender knowing the borrower's true type, let us assume the informed lender receives a signal $\tilde{X}=\left\{\tilde{x}_{L}, \tilde{x}_{H}\right\}$ about the borrower's type. In particular:

$$
\operatorname{Pr}\left(X_{i}=X_{L} \mid \tilde{x}_{L}\right)=q>\frac{1}{2}
$$

Therefore, in this version of the model, the informed lender still has some uncertainty over the firm's type.

Then, let us assume that the informed lender does not want to lend if she observes the low signal $\tilde{x}_{L}$, formally:

$$
R\left[X_{L} q+X_{H}(1-q)\right]<\rho<R\left[X_{L}(1-q)+X_{H} q\right]
$$


This assumption is the analogue of equation (1) in the basic model. This equation states that if the informed lender receives a signal $\tilde{x}_{L}$ the maximum expected return is strictly less than the cost of capital.

Altering the timing of the model slightly:

(1) Nature chooses the firm's type $X_{i}$.

(2) The informed lender observes $\tilde{X}_{i}$.

(3) The informed and uninformed lenders make simultaneous bids $\left(k_{j}\right)$ over how much to lend at an interest rate $R$.

(4) The firm accepts none, one, or both of the loan offers.

(5) The project is successful, or not, and payoffs are assigned.

\subsubsection{Equilibrium.}

Corollary 1. A Perfect Bayesian equilibrium of the game is:

$$
\begin{aligned}
\text { (Informed lender) } \tilde{k}_{I}^{L} & =0, \tilde{k}_{I}^{H}=\tilde{k}_{I}^{H *}>0 \\
\text { (Uninformed lender) } k_{N} & =k_{N}^{*} \geq 0 \\
\text { (Firm) } s_{f}^{i} & =(\text { Acc }, \text { Acc })
\end{aligned}
$$

Proof. The proof of this is very similar to the proof of Proposition 1 The details are in the appendix.

Proposition 5. As the informed lender's signal of the borrower improves, the difference in expected lending increases. Formally:

$$
\tilde{\Delta} \equiv[(1-q) \gamma+q(1-\gamma)] \tilde{k}_{I}-k_{N} \text { is increasing in } q
$$

Proof. The proof of this is very similar to the proof of Proposition 4. The details are in the appendix.

The intuition for Proposition 5 follows from: As the informed lender's information becomes better, the informed lender is better able to target the good firms, therefore, the informed lender is more willing to offer bigger loans. This leads to the uninformed lender making smaller profits on the good borrowers (more competition), and subsequently reducing the size of her loan offers. 
4.6. Mapping the model to the data. Empirical predictions of proposition 2; The informed lenders will offer larger loans on average to those firms for whom they have better information following the reform.

Empirical predictions of proposition 3 The informed lenders will have default rates similar to the uninformed lender following the reform on those firms they both continue to serve, but the uninformed lender will have greater overdue rates overall.

Empirical predictions of proposition 4: The informed lenders will lend more to those firms where the quantity of lemons is greatest, since determining which firms are good credit risks, and which are not, is more important as we increase the proportion of bad types. Generally, those firms which have had an amount overdue in the past would be the riskiest firms. We would expect the effect of the reform to be the largest on those firms.

Empirical predictions of proposition 5. As we increase the information advantage for the informed lender, the expected difference in loan sizes will increase. We will proxy for effects of the informational advantage by examining the effects of the reform on those lenders who lent to a greater number of a firm's group, and by carefully examining the strength of the interfirm relationships between firms.

\section{The Effect of the Reform on a Firm's Source of Credit}

5.1. Econometric specification. The paper's main question is: What is the effect of asymmetric information between lenders on a firm's source of credit? We answer this question using a reform that exogenously reduced banks information about firms in a way that varied across bank-firm lending pairs. To test the model's predictions, we examine whether those banks with private information about a firm's group were more likely than other banks to renew a firm's loans following the reform.

In the paper's main specifications, a "group" is defined using a relatively narrow definition: An overlapping director must own a substantial amount of equity in two firms before those two firms are grouped together. We will demonstrate that altering the definition of a group in economically meaningful ways will lead to different results.

Definition 1. Firm $f$ 's group is all other firms with whom firm $f$ has a common director and at least $25 \%$ shareholding in both firms as of December 2004 ${ }^{14}$

The main source of identification in the paper will be to compare borrowing amounts for the same firm from two different lenders, before and after the regulation, where each lender lends to different members in the group at baseline (so we are restricting the sample

\footnotetext{
${ }^{14}$ This definition of groups allows firms to be in multiple groups and that groups are not mutually exclusive. Therefore, a group is defined with respect to a firm. For a quick pictorial representation how firms can be in multiple groups see figure 4
} 
FIgURE 3. Identification Strategy: comparing loan details for the same firm borrowing from two different banks.

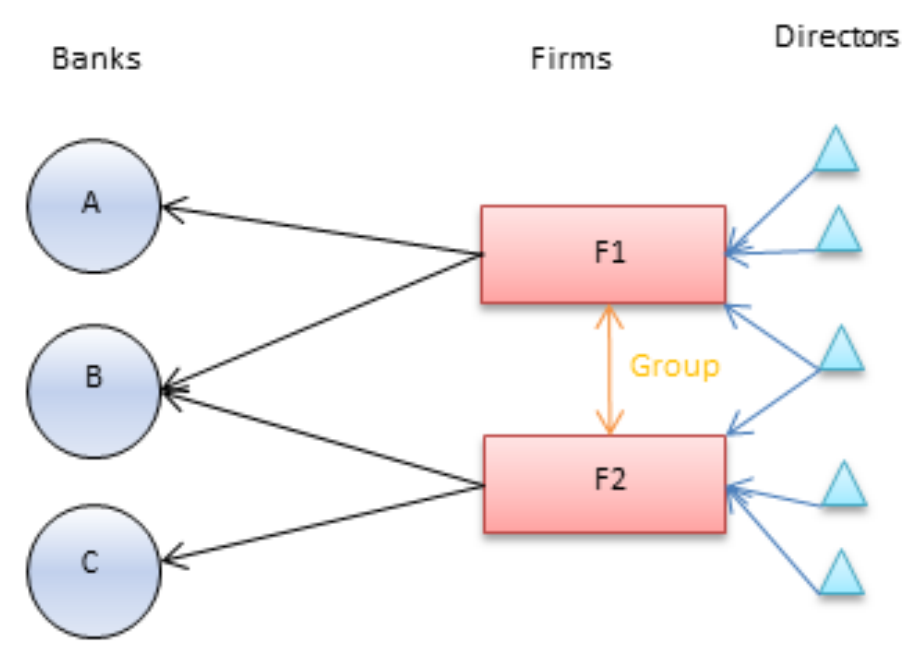

to lenders who were already lending before the reform, and therefore, by definition have some information). For example, assume there are two firms "F1" and "F2" who are in the same group. Both "F1" and "F2" borrow from two banks each in December 2004. "F1" borrows from banks "A" and "B" and "F2" borrows from banks "B" and "C," as shown in Figure 3 .

Notice that bank "B" is lending to both firms in the group in December 2004, whereas bank " $\mathrm{A}$ " and bank "C" only lend to one firm in the group. After the regulation change, only bank "B" is able to compile the group's lending.

Definition 2. A loan from bank $b$ to firm $f$ is labeled a "informed loan" if at least one other member of firm $f$ 's group borrows from the same bank, $b$, in December 2004 (baseline). Similarly, a loan from bank $b$ to firm $f$ is labeled an "uninformed loan" if no other member of firm $f$ 's group borrows from the same bank, $b$, in December 2004.

In the stylized example in figure 3, firm F1 has one informed loan (the loan with bank "B") and one uninformed loan (the loan with bank "A"). The paper's identification will be examining how lending changes between the informed and uninformed loans, before and after the regulation change.

We estimate equations of the form: 


$$
Y_{b f t}=a_{b f}+a_{b t}+a_{f t}+\beta_{1} \times \text { post }_{t} \times \operatorname{Informed}_{b f}+\epsilon_{b f t}
$$

The unit of observation is at the bank-firm-date level, so $Y_{b f t}$ is the variable of interest at bank $b$, firm $f$ in month $t$. For example, it could be the size of the loan outstanding by firm $f$ at bank $b$, in month $t$. Informed $b f$ is a dummy variable equal to one if the loan between bank $b$ and firm $f$ is an informed loan. Post is a dummy variable equal to one for a loan after April 2006.

The standard errors $\epsilon_{b f t}$ are clustered at the level of the component - at the level such that every firm within the component has at least one indirect link to every other firm in the component.15

All the main regressions contain a firm $\times$ date fixed effect, $\alpha_{f t}$. This fixed effect implies that we are estimating the difference in firm lending using differences for the same firm and in the same month. Therefore, we are estimating $\beta_{1}$ from only those firms that have both an informed and an uninformed loan. We have a total of 449 firms and 1,784 loans in December 2004 who had both an informed and an uninformed lending relationship. Table 3 presents more details about the firms which identify $\beta_{1}$.

Figure 11 demonstrates that the firms who identify $\beta_{1}$ in general have larger loans. This is in part mechanical, since we are only identifying the effect of the policy from those firms who have at least two loans.

Including the fixed effect $a_{b t}$ ensures that we are allowing for any aggregate change in bank lending for each month, and the fixed effect $a_{b f}$ ensures we are controlling for any firm-bank specificity.

This section restricts attention to those banks that were lending in December 2004, therefore, the paper does not include any new relationship in the analysis because any new borrowing relationship may be endogenous. Furthermore, in the estimation procedure, firms who discontinue relationships with all of their original lenders are dropped 16 .

5.1.1. Outcomes of interest. There are three main outcomes of interest in the paper:

- Log loan $\operatorname{size}_{b t}$

- Renewed $\operatorname{loan}_{b f t}$

\footnotetext{
${ }^{15} \mathrm{~A}$ component is defined as the set of firms for whom their exists a direct or indirect link to every other firm within the component. A direct link between two firms is defined if there is at least one mutual director who owns at least $25 \%$ of each firm and an indirect link exists between two firms if there is at least one path of direct links between the two firms. Conceptually, if firm $f$ is in component $c$ then firm $f$ 's group must be a subset of a component $c$. The definition of a link, is similar to the one used in all benchmark specifications.

${ }^{16}$ The paper shows robustness results showing similar effects with the set of firm-bank connections which always have an active borrowing relationship.
} 
- Overdue $_{b f t}$

"Log loan size $_{b t}$ " is defined as the log of real funded loan size outstanding in date $t$ at bank $b$ by firm $f$. If there is no loan observed this is coded in the data as equal to the minimum of what is observable in the data set (the log of 500,000 Rs.).

"Renewed loan "ft $_{t}$ is defined as whether firm $f$ at bank $b$ at date $t$ has an outstanding funded loan amount above 500,000 Rs. (in 2004 Pakistani Rupees).

"Overdue ${ }_{b f}$ " is defined as whether firm $f$ at bank $b$ at date $t$ is overdue at date $t$. There are certain endogeneity issues when looking at overdue rates because a firm can only go overdue if a firm has a loan which will be shown to be a function of the amount of information a bank has about a borrower. This is discussed in greater detail in the results.

5.2. Results. We explore the implications of differentially informed lenders on a firm's source of credit in three ways: (i) to explore the overall effects of the reform, we estimate the difference in loan sizes between informed and uninformed lenders (ii) to explore the role of private information, we estimate how the difference in loan sizes changes as we use various measures of informed lenders and (iii) to explore whether there were heterogeneous effects for different firms, we estimate the effect of the reform on different firm sizes and differing credit risks.

5.2.1. Following the reform, loan sizes were relatively larger within informed banking relationships. Our main results indicate that when public information available to banks was reduced, the change caused those banks to lend more to firms for whom they had greater private information. Banks with a better knowledge of a firm's group were more likely to renew the credit facility, and grant greater credit for renewed loans.

This is most strikingly represented in Figure 12. Figure 12 plots the coefficients from a regression of loan renewal on an informed dummy, interacted with date dummies, and all second-order fixed effects, firm $\times$ date, date $\times$ bank, and firm $\times$ bank. The figure clearly shows that the difference in renewal rates between informed and uninformed loans is relatively constant before the reform, suggesting that the common trends identifying assumption holds. Following the reform, there is a sharp and persistent increase in the renewals of informed loans relative to uninformed loans. This indicates that the reform causes banks to increase their lending to firms for which they have more information.

Table 4 shows the estimates for the policy's effect under different specifications. The first column contains date, firm and bank fixed effects, and therefore is being estimated from between- and within-firm differences. Columns 2-6 all include a firm interacted with date fixed effects. This ensures that we only use the set of borrowers who have both, an 
informed and uninformed banking relationship, to identify whether an informed banking relationship was more likely to be renewed.

The estimates are all relatively similar and the various specifications suggest that an informed banking relationship was between 5-8\% more likely to be renewed than an uninformed banking relationship for the same firm. The preferred specification is column 6 , which includes all three second order-fixed effects. In doing so, we are controlling for any aggregate changes in a bank's willingness to offer credit over time and firm-bank match specificity, and identifying the effect from firms which had both, an informed and uninformed lending relationship. Figure 12 is the graphical counterpart of the regression in column 6 , except that we interact date dummies with the informed dummy variable.

While the previous results examine the effects of the policy on the extensive margin, here we can examine if the total size of the funded loan was larger in an informed banking relationship after the regulation change.

Figure 13 plots the coefficients from the log loan size on an informed dummy variable interacted with date dummies and all second-order fixed effects ${ }^{17}$ Though the estimates are less precise than the extensive margin, we clearly see a similar trend as the extensive margin. Table 5 shows the same specifications as Table 4 but the dependent variable is the log of real funded loan size. The various estimates suggest that an informed banking relationship was between $8-12 \%$ larger following the policy change.

As a robustness check, we restrict the sample to those lending relationships which last until June 2008 or December 2008, and compare loan balances across informed and uninformed banking relationships for the same firm. Table 6 shows the estimates from this regression. Although power is an issue, the size of the effects look similar across the different specifications to the results in table 5 .

The SBP only required banks to report details of a loan if the firm's total loan outstanding was greater than 500,000 Rupees $(\$ 8,500)$ could lead to the following bias in our results. Loans which were initially just above the cutoff could be partially repaid, subsequently falling below the 500,000 Rupees threshold and as such incorrectly categorized as a nonrenewed loan. This is a greater concern since the uninformed loans are in general smaller than the informed loans. Table 7 excludes firms which had a loan close to the cutoff in December 2004. The observed effect of the policy seems consistent when we exclude firms with a loans below $\$ 12,750, \$ 17,000$ or $\$ 21,250$ in December 2004 . This suggests that the censoring of the data at 500,000 Rupees does not affect the results.

\footnotetext{
${ }^{17}$ If a loan is not observed, we code the loan size to be the log of 500,000 Rs., which is the minimum threshold at which we are able to observe a loan.
} 
5.2.2. There were substantial differences in the effect of the policy on the credit market depending on the strength of the interfirm relationship. The results in section 5.2.1 demonstrate that the reform led banks with private information about a group to lend more than other banks. Here we consider whether the effects vary by the amount of private information an informed lender has. In particular we consider variation in: the strength of the observed interfirm relationship and the number of firms who borrow from the same lender.

We observe substantial heterogeneity in the measured effect of the reform depending on the level of control implied within the interfirm relationship. If we separate the interfirm relationships according to the amount of equity a director owns, it is clear there was little or no effect on those firms which had only overlapping directors. Further, the size of the effect was increasing in the interfirm relationship according to equity levels, which is a proxy for control. Therefore, this suggests that merely overlapping directors had no informational content on a firm's creditworthiness.

Table 8 and figure 14 shows the effect of the reform for different levels of equity held by a mutual director. If a bank observed two firms who shared a director who owned at least 40 percent of both firms, the bank was $7.6 \%$ more likely to renew a loan from either firm, compared to a bank who only observed one firm. However if a director had no ownership stake in either firm, the bank was only $2.5 \%$ (not statistically significant) more likely to renew their loans.

These results are consistent with proposition 5: As the information differential between informed and uninformed lenders increases, the uninformed lender will lend less.

An additional measure of the strength of the firm-bank relationship is observing the number of other group firms who borrow from the same bank. If more firms in the same group borrow from a bank, that lender is expected to have more private information about interfirm links, and therefore be more willing to lend. Tables 9 and figure 15 demonstrate that as we increase the number of interfirm relationships borrowing from the same bank, the effect of the policy was much larger. Those bank-firm pairs where the bank had greater information over the group are observed to increase their lending more.

5.2.3. The effect of the change in information was predominantly felt by small to medium sized firms. From a policy perspective it is important to examine what type of firms were most affected by the reform. We examine if the effect varies by firm size.

Table 10 and figure 16 show the effects of the policy on the likelihood of a loan being renewed by different deciles, where the deciles are created according to the total amount the firm borrows at baseline. We see almost no effect (and certainly no statistically significant effect) on the largest decile of borrowers. 
These results suggest that public information was most important for small to medium sized firms. These results can be interpreted in two ways: (i) the relative cost of procuring information is largest for the smallest firms or (ii) information about the largest firm's groups is already well known by the banks. We consider each possibility in turn.

As discussed in section 3.2 , banks procure more information about a firm in addition to what is provided by the SBP's credit registry service. This information - such as calling other bank managers, or accessing the SECP database - may be costly to acquire. It is plausible that loan officers will conduct greater scrutiny over larger loans (assuming the cost of default is linear in loan size). Consequently the effect of the regulation change would be largest on those firms that borrowed the least (as this is where the proportional cost of acquiring more information to dollar lent is the largest).

Mr. Mansoor Siddiqi, the ex-Director Banking Policy and Regulation Department at the SBP remarked in an interview: "The number of corporate [firms] is not large in Pakistan therefore people tend to know about reputations," further strengthening the assertion that we would expect little to no effect on those firms that had large groups. Table 11 and figure 11 show the effects of the policy on the likelihood of a loan being renewed by different deciles, where the deciles are created according to the total amount the firm's group borrows at baseline. Similar to the results in table 10 , we see no effect on those firms who are part of the largest groups.

5.2.4. The effect of the policy was largest on those firms who were overdue on a loan in December 2004. Another way to analyze how the reform may have had heterogeneous effects across firms is to consider those firms who were observably worse credit risks prior to the reform. Firms that had loans overdue in December 2004 are expected to be at the greatest risk of being overdue in the future. Further, the problem of incomplete information on the firm's group may be more pronounced, since one firm with an amount overdue might indicate financial distress within the wider group. So, a lending institution may be more willing to lend to a firm if it is able to inspect the wider set of group firms too. Also, when one firm defaults, the institution could react by reducing lending to the group at large.

Therefore, a firm that has an amount overdue may be more likely to borrow more from an informed banking relationship after the regulation change. Confirming this economic intuition, these results are shown in table 12 .

These results are consistent with proposition 4 in the model: In environments where there is largest number of lemons, the uninformed lender is relatively more likely to stop lending. 
5.2.5. Overdue rates are similar across informed and uninformed banking relationships. The previous results highlighted how the reform affected who was able to borrow. In this section we examine if the reform affected overdue rates.

The reduction in public information may alter a firm's incentive to default on a loan for two reasons. First, a firm may be more willing to be overdue because the impact on the rest of the firm's group will be limited. Second, the lender would be less willing to offer a loan. In section 5.2.1 we demonstrated that the uninformed lender was $5.4 \%$ less likely to renew a firm's loan than the informed lender.

Only if all loans were renewed would we be able to identify the effect of the change information on a firm's incentive to default.

However, if strategic default was a key problem in these corporate markets you would expect the relative likelihood of a loan being overdue to be greater at an uninformed lender than an informed lender for the same firm. The firm is less likely to have his loan renewed by the uninformed lender, reducing the dynamic incentive to repay the loan. Also, the repercussions on a firm's group would be smaller at an uninformed lender. Therefore, the absence of any differential on the likelihood of a loan being overdue between an informed and uninformed lender suggests there was no greater strategic default by the firm upon the uninformed lender.

The regressions in column 2 of Table 13 , show little difference in overdue rates between informed and uninformed banking relationships. Column 2, which estimates the difference in the likelihood of a loan being overdue at an informed and uninformed lender for the same firm, shows a relatively precise zero estimate. Column 2 suggests there was no strategic default by the firm following the regulation reform - even though they were less likely to have their loan renewed.

Column 1 is estimated from both, between-firm and within-firm differences, since it does not include a firm $\times$ date fixed effect. Column 1 suggests uninformed lenders select a worse set of loans to renew than informed lenders which is consistent with the proposition 3 . In particular, defaults rates for uninformed lenders were $3 \%$ higher than informed lenders following the reform.

\section{The Effect of the Reform on a Firm's Access to Total Credit}

In the previous section we established that a firm was more likely to receive a loan from an informed lender following the reform. In this section we wish to examine whether those firms with such informed lenders were more likely to have larger credit lines following the reform. Consequently, we ask: Did firms merely substitute their lending partners and 
receive the same total loan amounts? Or, did the reform lead to real effects in how much a firm was able to borrow?

\subsection{Econometric specification.}

Definition 3. Firm $f$ has an informed lending relationship if firm $f$ borrows from a bank who also lends to at least one other member of firm f's group in December 2004.

To examine whether the reform affected a firm's access to credit we create a dummy variable "informed lender" which takes a value of " 1 " if the firm had an informed lending relationship in December 2004.

We identify the effect of the reform by comparing total loan amounts for those firms with and without an informed lending relationship before and after the regulation. Formally, we estimate an equation of the form:

$$
Y_{f t}=a_{f}+a_{t}+\beta_{1} \times \text { post }_{t} \times \text { Informed Lender } f+\gamma X_{f t}+\epsilon_{f t}
$$

Where $Y_{f t}$ is the $\log$ of real total funded borrowings by firm $f$ in month $t$. Informed lender $f$ is a dummy variable equal to one, if the firm has at least one informed lending relationship in December 2004. Post is a dummy variable equal to one for a loan after April 2006. $a_{f}$ and $a_{t}$ are firm and date fixed effects respectively. In section (5) our identification relied on comparing the loan outcomes for the same firm, whereas in this section we rely on comparing the total credit borrowed between firms. Consequently, to allow for firm differences across regions and sectors, we include a set of firm by time controls $X_{f t}$, such as the firm's province interacted with time fixed effects.

As before, the standard errors $\epsilon_{f t}$ are clustered at the level of the component - at the level such that every firm within the component has at least one indirect link to every other firm in the component. As in the previous section, we do not observe loans smaller than 500,000 Rupees. Therefore, if we do not observe any loan for a firm, we code that firm's total borrowings to be 500,000 Rupees.

\subsection{Results.}

6.2.1. Firms with an informed lending relationship borrowed more after the reform. Table 14 estimates the effect of the reform on firms who had an informed lending relationship in December 2004. The difference-in-difference estimates suggest that those firms with an informed lender were able to borrow $11 \%-14 \%$ more following the reform, compared to firms with no informed lender. The results are robust to various controls such as a 
province interacted with date fixed effect and business sector interacted with date fixed effect 18

Combining the results from section 5.2.1 with the results in table 14 suggests that the reform had two key effects: (i) lenders with greater information lent more to the same firm following the reform and (ii) those firms with informed lenders were able to access more credit following the reform.

This suggests that the reform not only led to a reallocation of lending across lenders but also led to real effects in the credit market by altering a firm's capacity to procure credit. Interpreting these results, the reduction in public information led to a reallocation of credit to borrowers for whom the lender had greater information. Ultimately, this disadvantaged firms who borrowed from banks which had limited information about their wider set of interfirm relationships.

6.2.2. The borrowing capacity of the smallest firms were most affected by the reform. The effect of the reform was greatest on the smallest firms' total borrowings. We have established that the reform had real effects on how much a firm was able to borrow. To further evaluate the welfare and policy implications, we ask: What type of firms were the most affected by the reform?

To answer this question we estimate the effect of the reform on different sized firms.

Table 15 estimates the effect of the reform on different deciles of firm size and whether they had an informed lending relationship in December 2004. The difference-in-difference estimates suggest that those firms in the smallest decile were the most affected by the reform.

Combining the results from section 5.2.3 suggests that public information was crucial for the smallest firms. Not only were the more informed lenders more likely to lend to the smallest firms, but the smallest firms with an informed loan were more likely to procure larger total borrowings. The change in total borrowing for the largest decile was not significantly different from zero. These results further support the evidence that the regulatory reform had significantly different effects for different sized firms. With the largest effects for the smallest firms.

\section{Conclusion}

Asymmetric information is a focal issue when studying credit markets. These information asymmetries may exist between a borrower and a lender, and between different lenders.

\footnotetext{
${ }^{18}$ It should be noted the although the results are robust to a group size specific time trend, the results are not robust to a group size fixed effect interacted with a date fixed effect.
} 
To investigate the implications of adverse selection among differentially informed lenders, we use a reform by the State Bank of Pakistan.

In April 2006, the State Bank of Pakistan instituted a credit registry reform which exogenously reduced public information about a firm's creditworthiness, and did so in a way that varied across firm-bank pairs.

First, we present a model of differentially informed lenders with adverse selection, which generates clear predictions on how the reform is expected to affect a bank's willingness to lend. The model predicts that those banks with greater private information about a firm would be more likely to continue to lend to that firm. Further, it may lead those lenders with the least information about a firm to stop lending.

Then, to test the model's predictions we utilize the natural experiment that the SBP's reform generated. We show empirically that the absence of public disclosure of group affiliation led to a reallocation of corporate borrowing. Those lenders who had greater private information were $5.4 \%$ more likely to renew a borrower's loan. Remarkably, this is true even for banks that had a pre-existing relationship with the firm, suggesting that the strength of prior relationships does not eliminate the problem of imperfect information.

Not only do we see a reallocation of corporate borrowing, we also demonstrate that those firms who borrowed from an informed lender were able to borrow $12.3 \%$ more than firms who borrowed from less informed lenders. Consequently, we show that the source of a firm's credit, as well as the total credit it could procure, were affected by the State Bank of Pakistan's reform.

The model suggests that the reduction in public information leads to a negative welfare effect. Firstly, the asymmetry of information reduces the contestability of the market, and secondly, the reduction in information amplifies adverse selection, subsequently increasing the misallocation of credit. Finally, when the severity of adverse selection becomes worst, the uninformed lenders may stop lending.

Ultimately, complex interfirm relationships can alter a borrower's incentives and ability to repay a loan - necessitating that a lender analyze the firm's creditworthiness and consider the firm's interfirm relationships. Public information about these relationships is key to reducing information asymmetries, both, between a borrower and a lender, and between lenders themselves. 


\section{REFERENCES}

G. A. Akerlof. The market for "lemons": Quality uncertainty and the market mechanism. The Quarterly Journal of Economics, pages 488-500, 1970. URL http://www.jstor. org/stable/10.2307/1879431.

H. V. Almeida and D. Wolfenzon. A theory of pyramidal ownership and family business groups. The Journal of Finance, 61(6):2637-2680, 2006. URL http://onlinelibrary . wiley.com/doi/10.1111/j.1540-6261.2006.01001.x/full.

L. M. Ausubel. Adverse selection in the credit card market. mimeo, 1999.

A. N. Berger and G. F. Udell. Relationship lending and lines of credit in small firm finance. Journal of business, pages 351-381, 1995.

M. Bertrand, P. Mehta, and S. Mullainathan. Ferreting out tunneling: An application to indian business groups. The Quarterly Journal of Economics, 117(1):121-148, 2002. URL http://qje.oxfordjournals .org/content/117/1/121. short.

S. Cole, M. Kanz, and L. Klapper. Incentivizing calculated risk-taking: Evidence from an experiment with commercial bank loan officers. Harvard Business School Finance Working Paper, (13-001), 2012. URL http://papers.ssrn.com/sol3/papers.cfm? abstract_id=2101648.

D. De Meza and D. C. Webb. Too much investment: A problem of asymmetric information. The Quarterly Journal of Economics, 102(2):281-292, 1987. URL http: //qje.oxfordjournals.org/content/102/2/281.short.

H. Degryse and P. Van Cayseele. Relationship lending within a bank-based system: Evidence from european small business data. Journal of Financial Intermediation, 9(1): 90-109, 2000.

M. A. Desai and D. Dharmapala. Corporate tax avoidance and firm value. The Review of Economics and Statistics, 91:537-546, 2009.

R. Gopalan, V. Nanda, and A. Seru. Affiliated firms and financial support: Evidence from indian business groups. Journal of Financial Economics, 86(3):759-795, 2007.

R. Haselmann, D. Schoenherr, and V. Vig. Lending in social networks. 2013.

A. Hertzberg, J. Liberti, and D. Paravisini. Information and incentives inside the firm: Evidence from loan officer rotation. The Journal of Finance, 65(3):795-828, 2010. URL http://onlinelibrary.wiley.com/doi/10.1111/j.1540-6261.2010. 01553.x/full.

A. Hertzberg, J. Liberti, and D. Paravisini. Public information and coordination: Evidence from a credit registry expansion. The Journal of Finance, 66(2):379-412, 2011. URL http://onlinelibrary.wiley.com/doi/10.1111/j.1540-6261.2010. $01637 . \mathrm{x} / \mathrm{full}$.

D. M. Jaffee and T. Russell. Imperfect information, uncertainty, and credit rationing. The Quarterly Journal of Economics, 90(4):651-666, 1976. URL http: 


\section{//qje.oxfordjournals.org/content/90/4/651.short.}

D. Karlan and J. Zinman. Observing unobservables: Identifying information asymmetries with a consumer credit field experiment. Econometrica, 77(6):1993-2008, 2009. URL http://onlinelibrary.wiley.com/doi/10.3982/ECTA5781/abstract.

A. Khwaja, A. Mian, and A. Qamar. Bank credit and business networks. Working Paper, 2011. URL http://papers.ssrn.com/sol3/papers.cfm?abstract_id=1763351.

A. I. Khwaja and A. Mian. Do lenders favor politically connected firms? rent provision in an emerging financial market. The Quarterly Journal of Economics, 120(4):1371-1411, 2005a. URL http://qje.oxfordjournals.org/content/120/4/1371. short.

A. I. Khwaja and A. Mian. Unchecked intermediaries: Price manipulation in an emerging stock market. Journal of Financial Economics, 78(1):203-241, 2005b. URL http: //www.sciencedirect.com/science/article/pii/S0304405X0500053X.

A. I. Khwaja and A. Mian. Tracing the impact of bank liquidity shocks: Evidence from an emerging market. The American Economic Review, pages 1413-1442, 2008. URL http://www.jstor.org/stable/10.2307/29730128.

Ministry of Finance. Money and credit. Pakistan Economic Survey 2006, 2006.

S. Morris and H. S. Shin. Social value of public information. The American Economic Review, 92(5):1521-1534, 2002. URL http://www.ingentaconnect.com/content/aea/ aer/2002/00000092/00000005/art00012.

D. Paravisini and A. Schoar. The information and agency effects of scores: Randomized evidence from credit committees. Technical report, Working paper, November 9, 2012.

M. A. Petersen and R. G. Rajan. The benefits of lending relationships: Evidence from small business data. The Journal of Finance, 49(1):3-37, 1994. URL http: //onlinelibrary.wiley.com/doi/10.1111/j.1540-6261.1994.tb04418.x/full.

State Bank of Pakistan. Group liabilities in the cib report. Prudential Regulation, May 29 th 2004.

J. C. Stein. Internal capital markets and the competition for corporate resources. The Journal of Finance, 52(1):111-133, 1997. URL http://onlinelibrary.wiley.com/ doi/10.1111/j.1540-6261.1997.tb03810.x/abstract.

J. E. Stiglitz and A. Weiss. Credit rationing in markets with imperfect information. The American economic review, 71(3):393-410, 1981. URL http://www.jstor.org/ stable/10.2307/1802787.

J. E. Stiglitz and A. Weiss. Incentive effects of terminations: Applications to the credit and labor markets. The American Economic Review, 73(5):912-927, 1983. URL http: //www.jstor.org/stable/10.2307/1814662.

J. Stroebel. The impact of asymmetric information about collateral values in mortgage lending. Working paper, 2013. 
O. E. Williamson. Markets and hierarchies. New York, pages 26-30, 1975. URL http://books .google.com/books?hl=en\&amp; lr=\&amp; id=pg-wGL12BjUC\&amp; oi= fnd\&amp;pg=PA106\&amp; dq=williamson+markets\&amp; ots=vTVuhry98j\&amp;sig= 5cyDWz8eedTXmZZlkrKm52BjDAI.

O. E. Williamson. The economics of organization: The transaction cost approach. American Journal of Sociology, pages 548-577, 1981. 


\section{Figures and TABles}

FigURE 4. Multiple overlapping groups
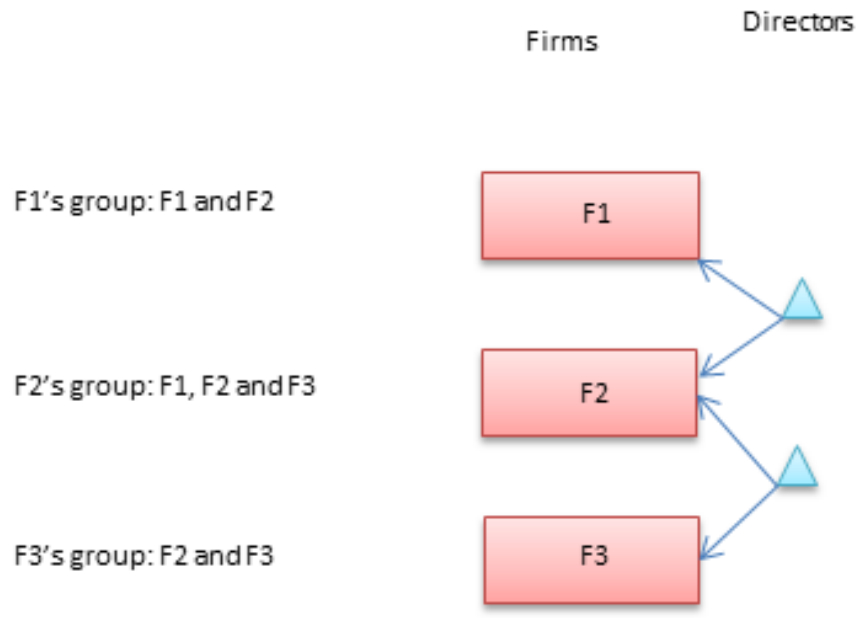

In the figure above there are three different firms and two directors but three different groups. Since a group is defined with respect to a firm (see definition 1), firm F1 only has a direct link to firm F2. Therefore, F1's group is only firms F1 and F2. 
Figure 5. The network of firm connections - using a cutoff of $25 \%$ equity

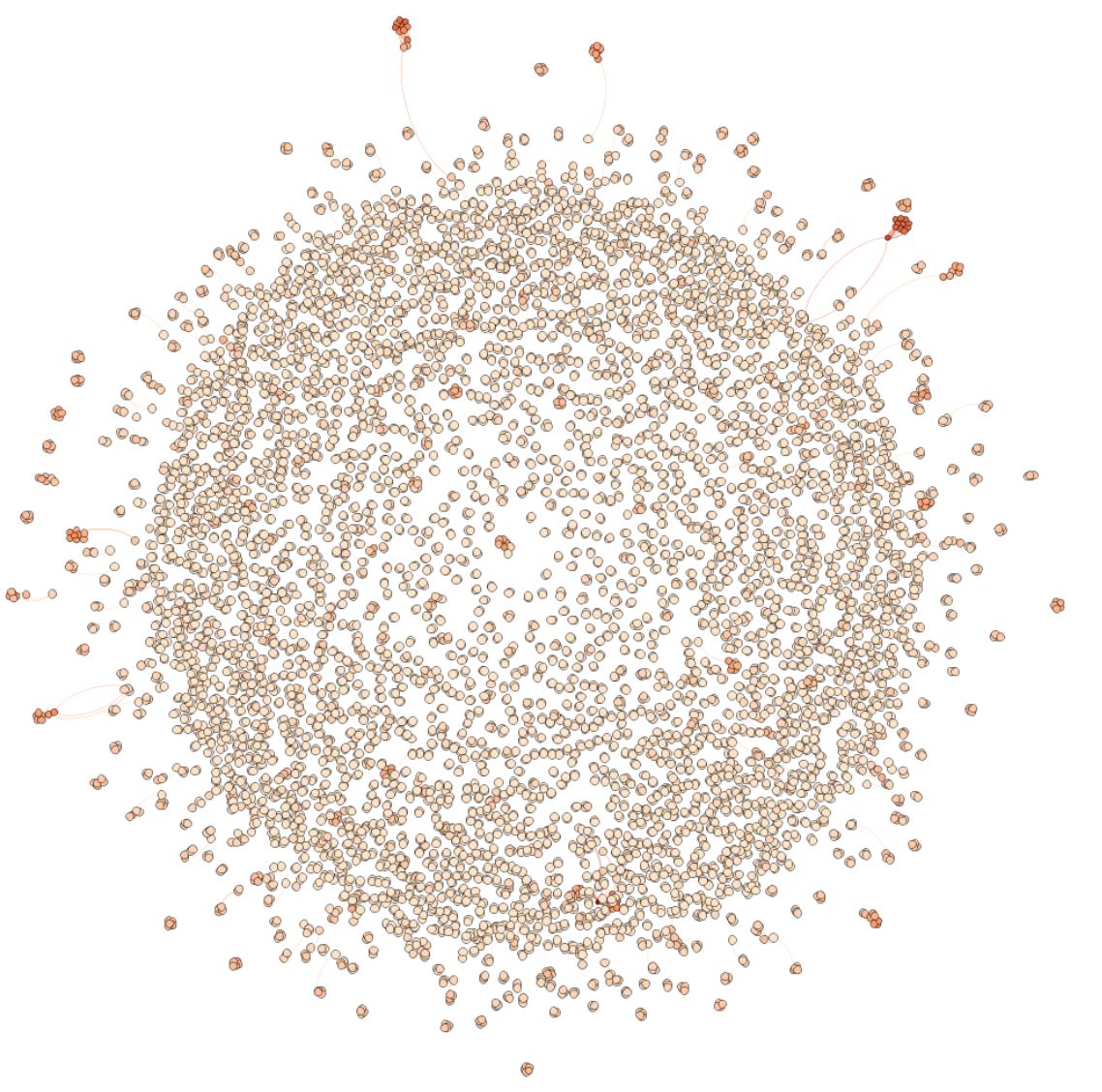

This is a network that shows interfirm relationships which only show connections between firms if they have at least one mutual director who owns more than $25 \%$ in both firms. Those firms with more interfirm relationships are colored in a darker red. The most visually striking aspect of this network is the lack of a single large component, and how the entire network is much less densely connected than the network compiled by merely mutual overlapping directors. 
FIGURE 6 . The number of connections for each firm

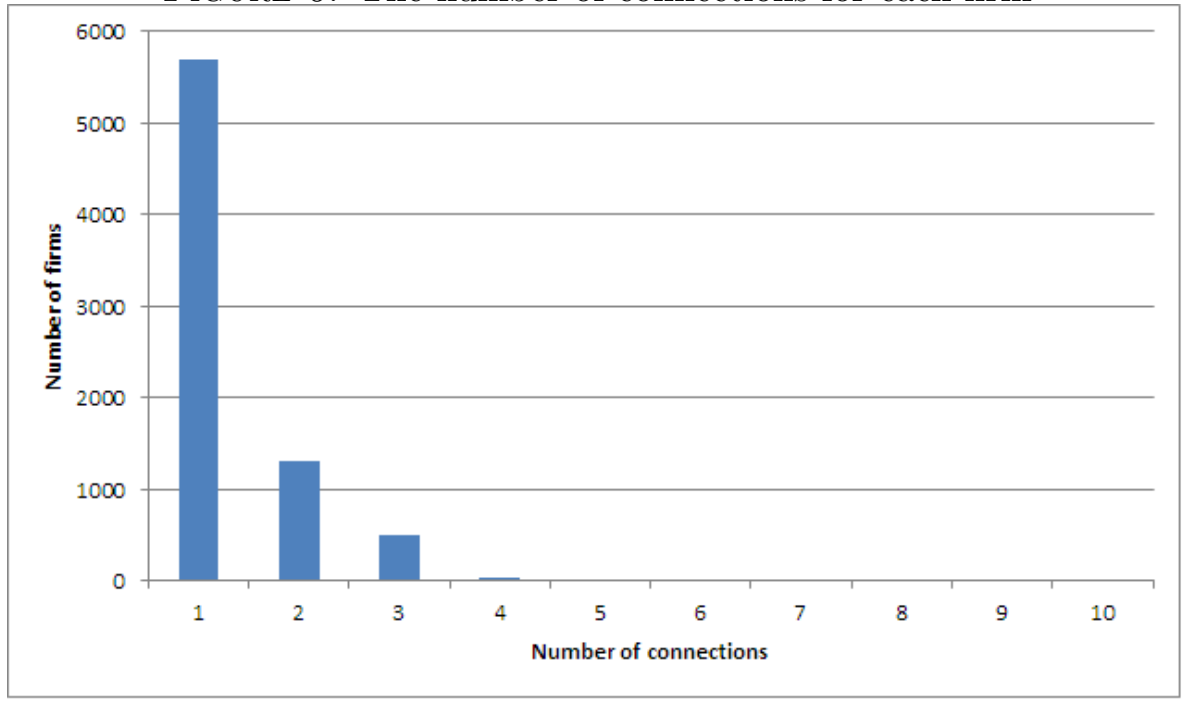

The graph displays the number of connections each firm possess in December 2004 where we define two firms to be linked if they share a mutual director who owns $25 \%$ or more of the firm's equity.

Figure 7 . The size of the components

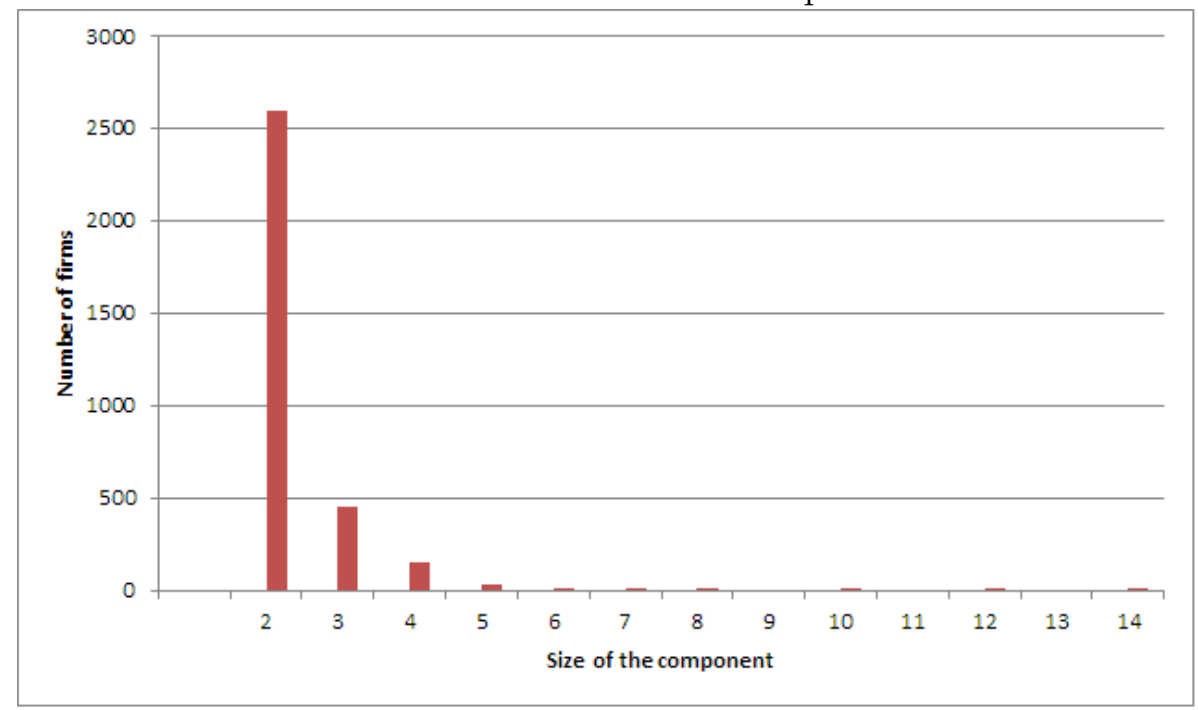

This graph details the size of each component, where we define two firms to be linked if they share a mutual director who owns $25 \%$ or more of the firm's equity. You can see the largest component is only 14 firms. 
FiguRE 8. The histogram of log total firm borrowings

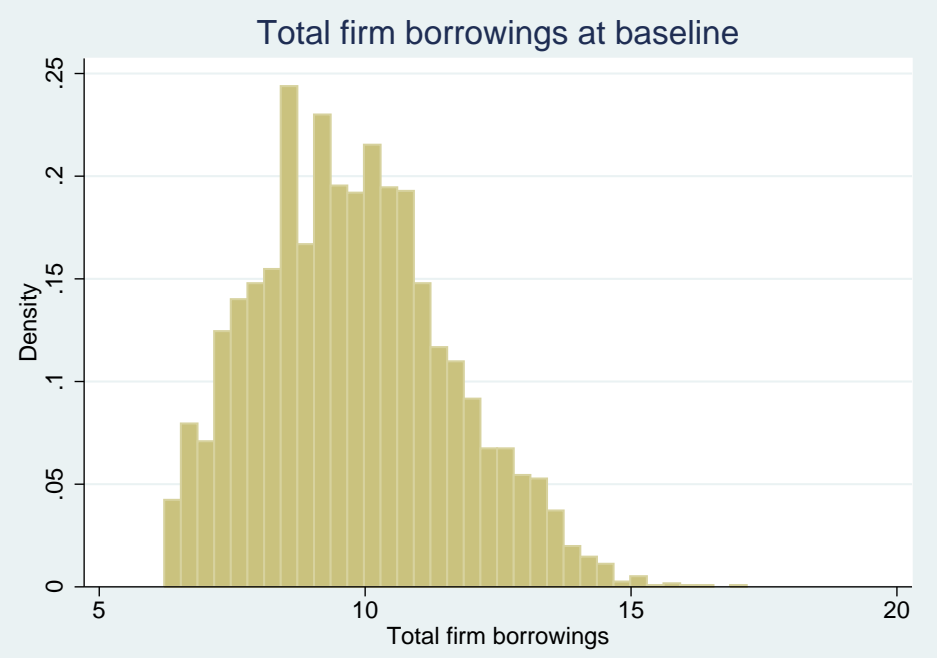

This is the histogram of the log total firm borrowings in December 2004 for group firms. Since, no loan below 500,000 Pk. Rupees was reported to the credit registry, there is a sharp cut-off at 6.2 , which is approximately the log of 500 .

Figure 9. The histogram of log loan size

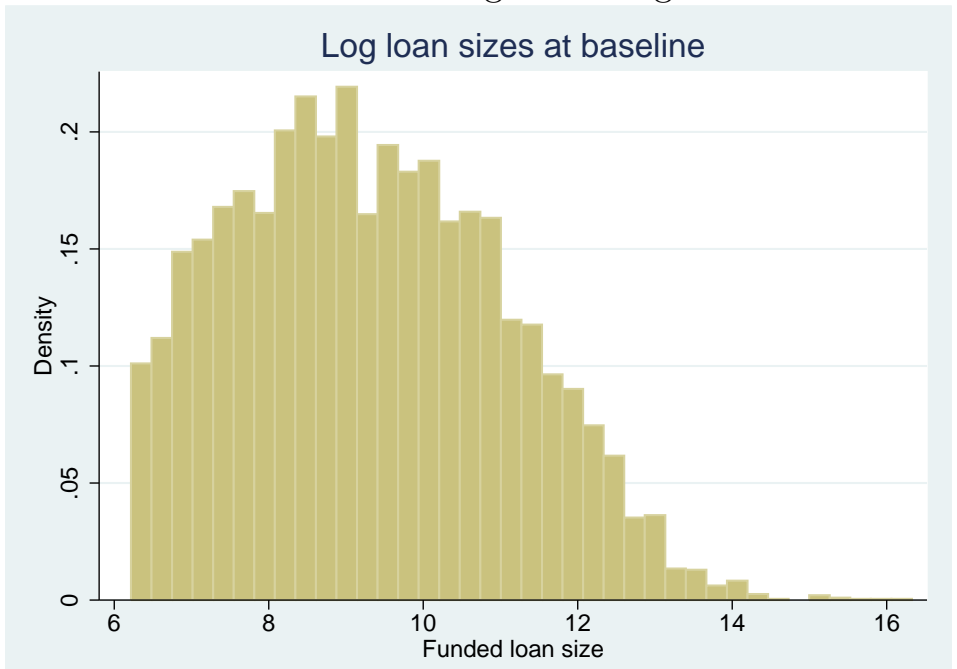

This is the histogram of the log loan size in December 2004 for group firms. Since, no loan below $500000 \mathrm{Pk}$. Rupees was reported to the credit registry, there is a sharp cut-off at 6.2 , which is approximately the log of 500 . 
Figure 10. The histogram of log loan size for informed and uninformed banking relationships

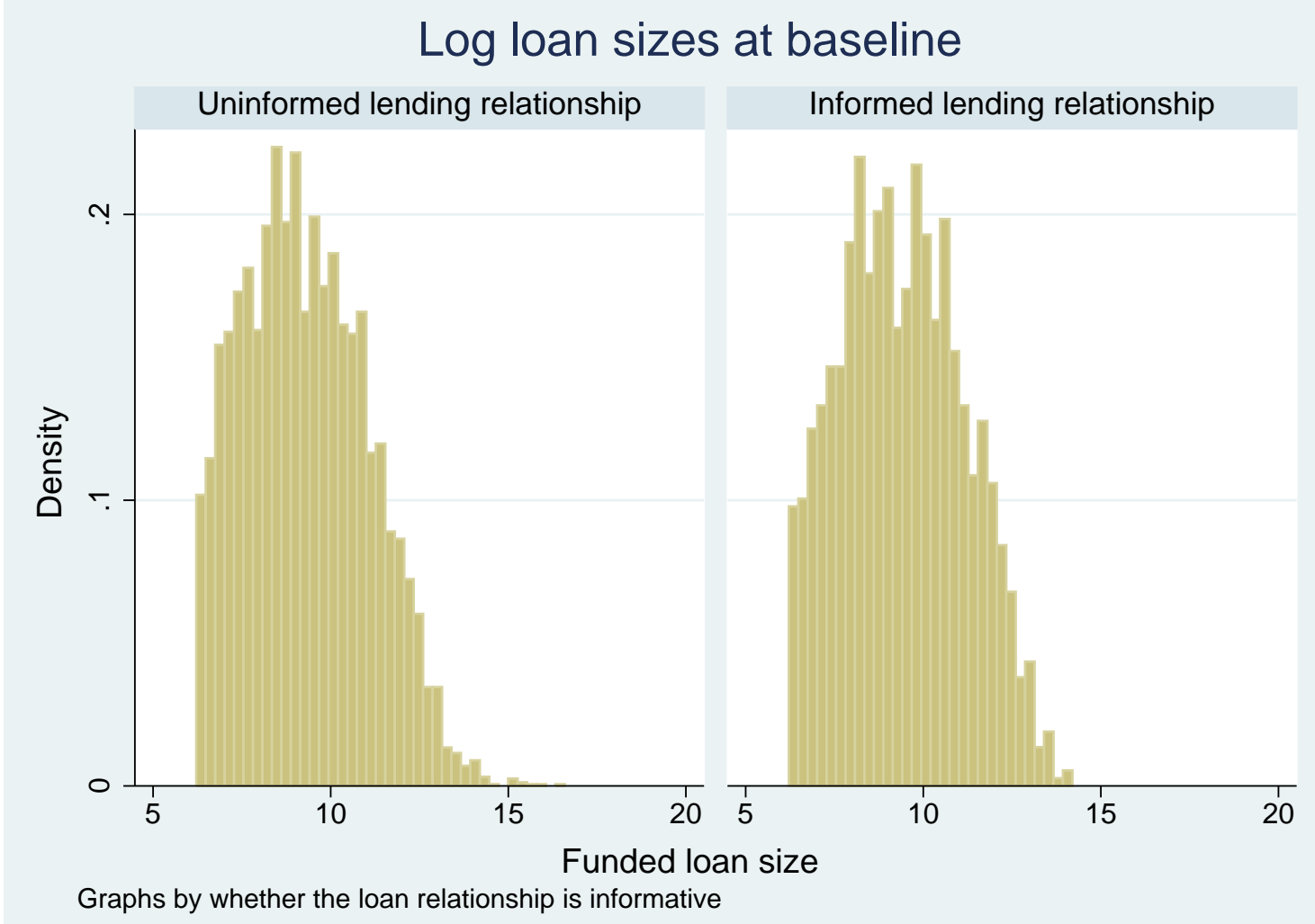

This is the histogram of the log loan size in December 2004 separated by informed and uninformed banking relationships. Since, no loan below 500,000 Pk. Rupees was reported to the credit registry, there is a sharp cut-off at 6.2 , which is approximately the log of 500 . We provide robustness tests to ensure the cutoff of small loans is not driving in our results. 
FiguRE 11. The histogram of total firm borrowings by lending relationship.

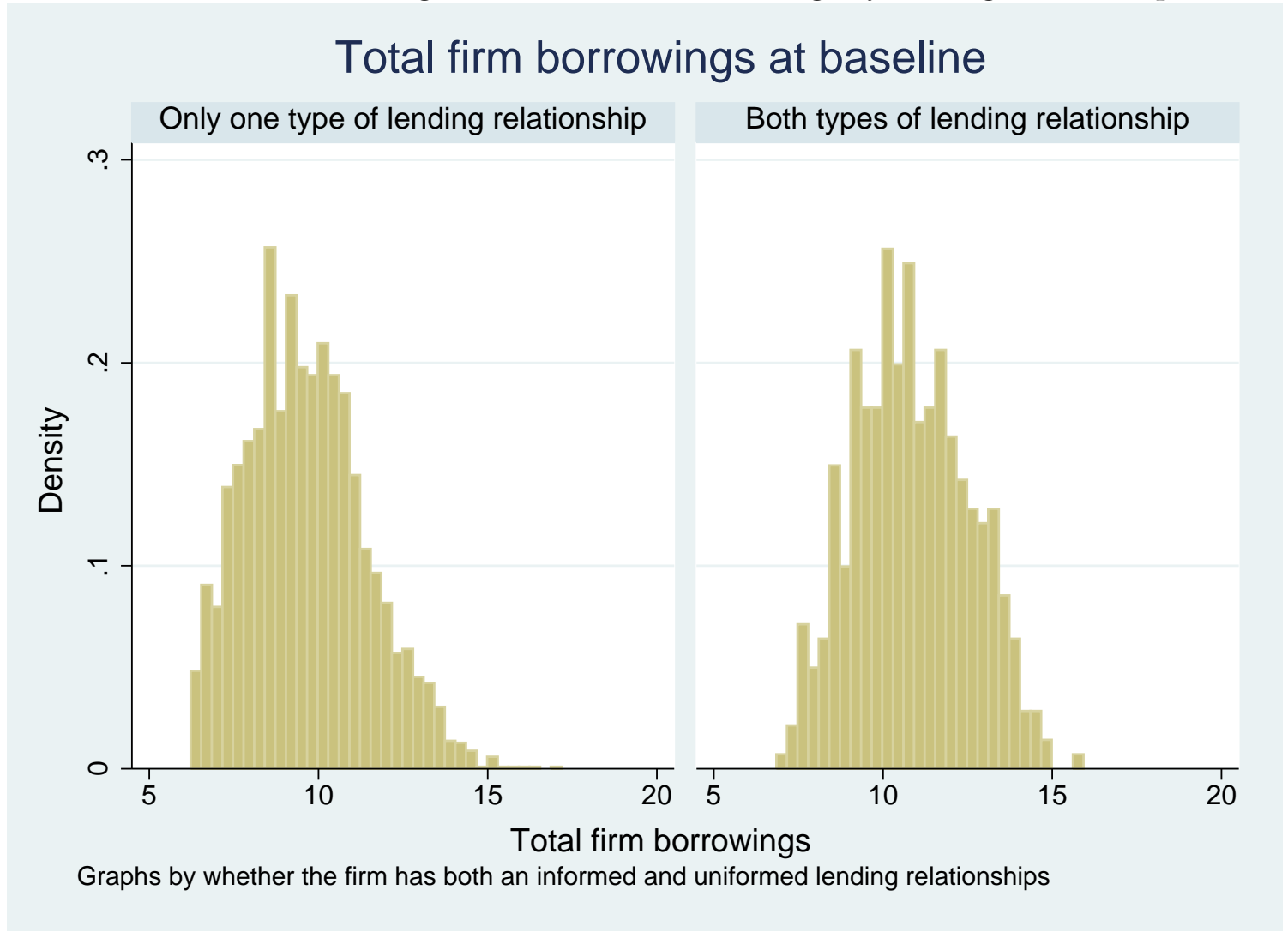

This is the histogram of total firm borrowing in December 2004 separated by the firms we are using for identification in section 5. We are only identifying the effects of the policy from the set of firms who borrow from both an informed and uniformed lender, therefore, the right panel demonstrates the distribution of total firm borrowings who have both an informed and uninformed lending relationship. As you would expect the distribution of total borrowings for firms who have both types of relationship are larger. This is partly mechanical effect as they must have at least two loans. The larger total borrowings at baseline would suggest these firms are also larger in general. 
FiguRE 12. The monthly coefficients for the difference in likelihood of a loan being renewed

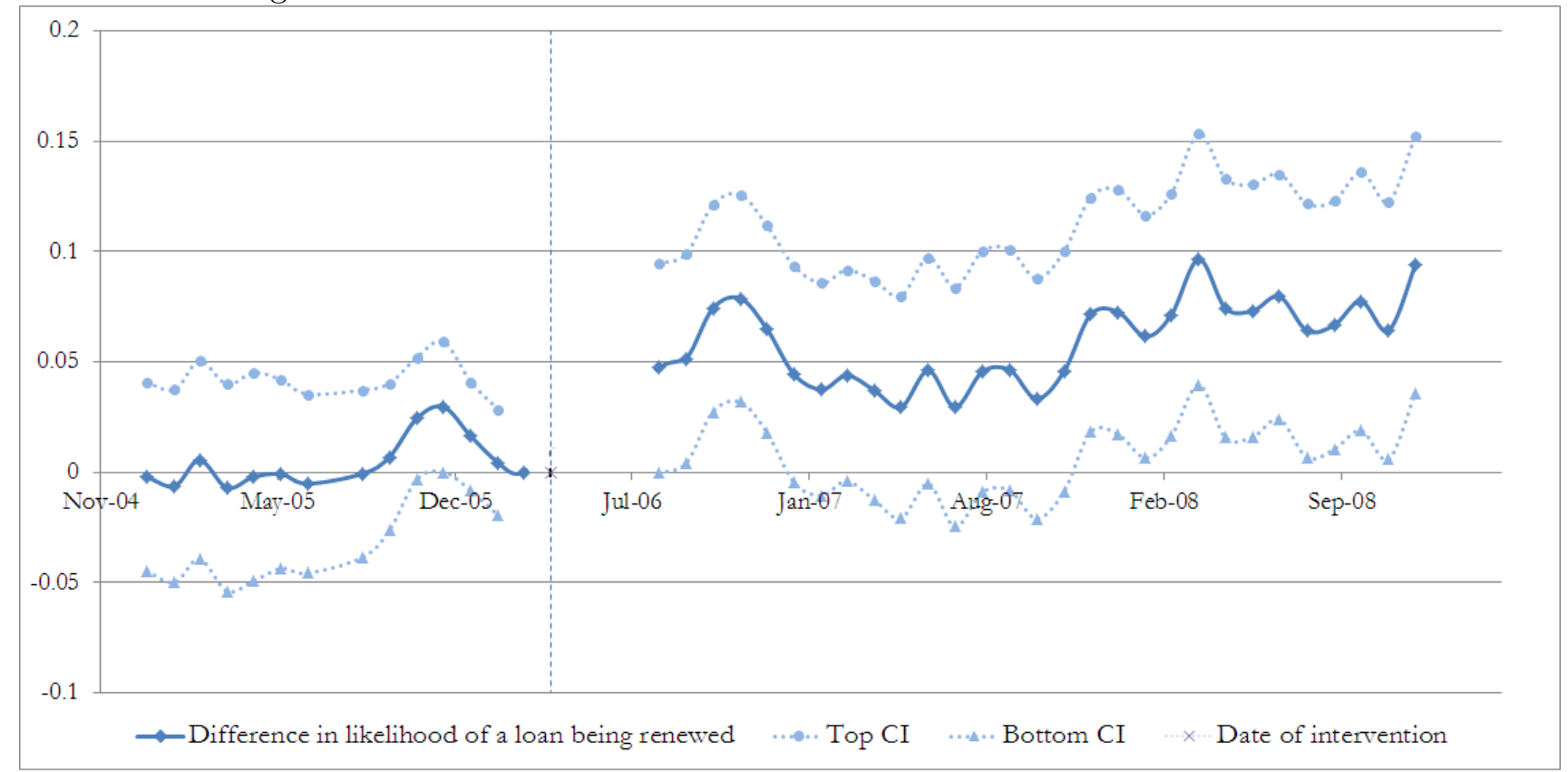

This is the monthly coefficient for informed loans, when using 'firm $\times$ date', 'firm $\times$ bank' and 'bank $\times$ date' fixed effects. The light blue lines are point-wise $95 \%$ confidence intervals. It is clearly evident there was a dramatic increase in the likelihood of a loan not being renewed for the same firm when the borrowing relationship was an uninformed banking relationship. 
Figure 13. The monthly coefficients for the difference in log loan size

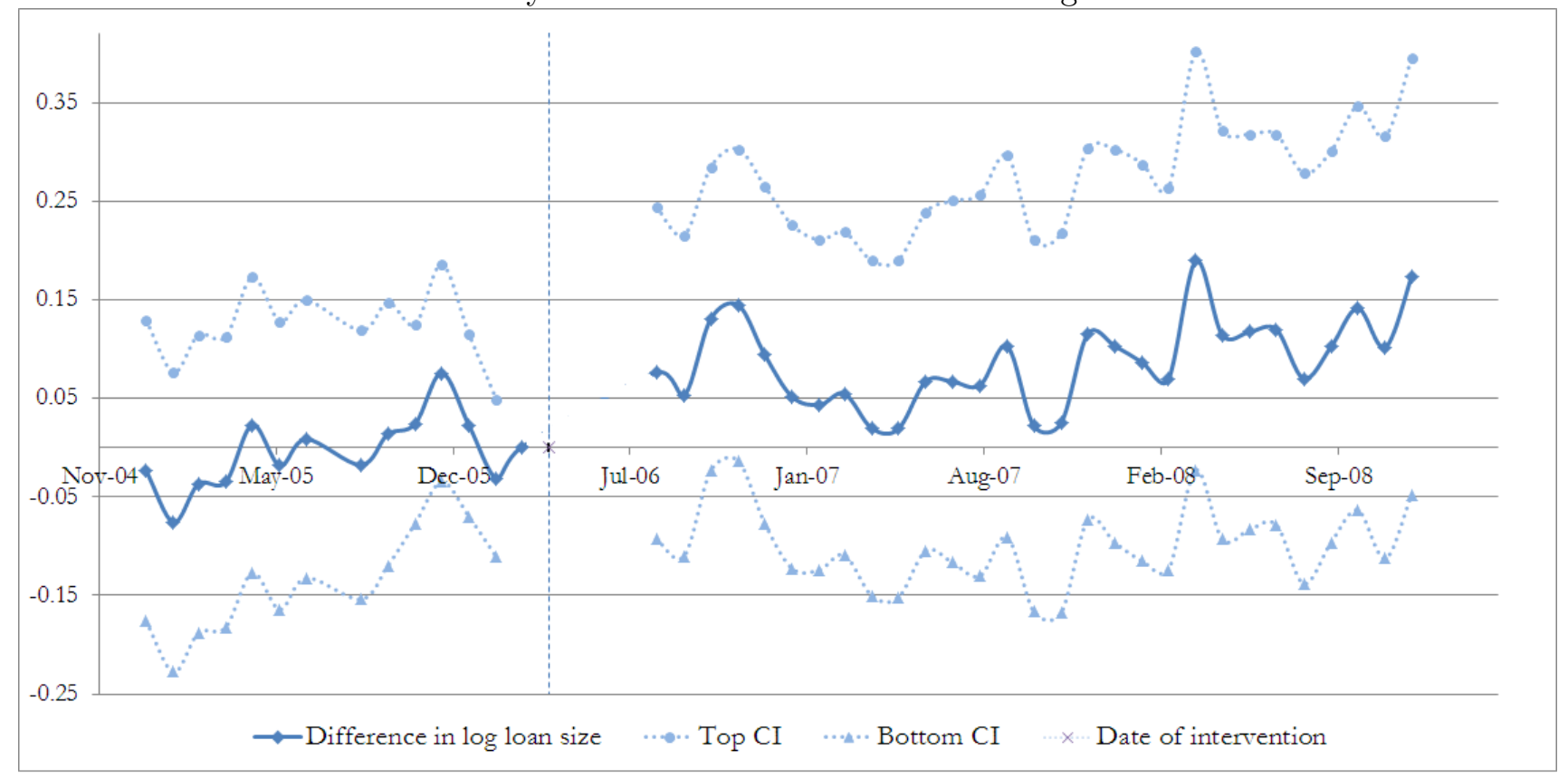

This is the monthly coefficient for informed loans, when using 'firm $\times$ date', 'firm $\times$ bank' and 'bank $\times$ date' fixed effects. The light blue lines are point-wise $95 \%$ confidence intervals. There does not seem to be a pre-trend in the difference in log loan sizes but there is some evidence that the loan sizes increased after the regulation change. 
Figure 14. The effect of the policy on the likelihood of the loan being renewed by different share thresholds.

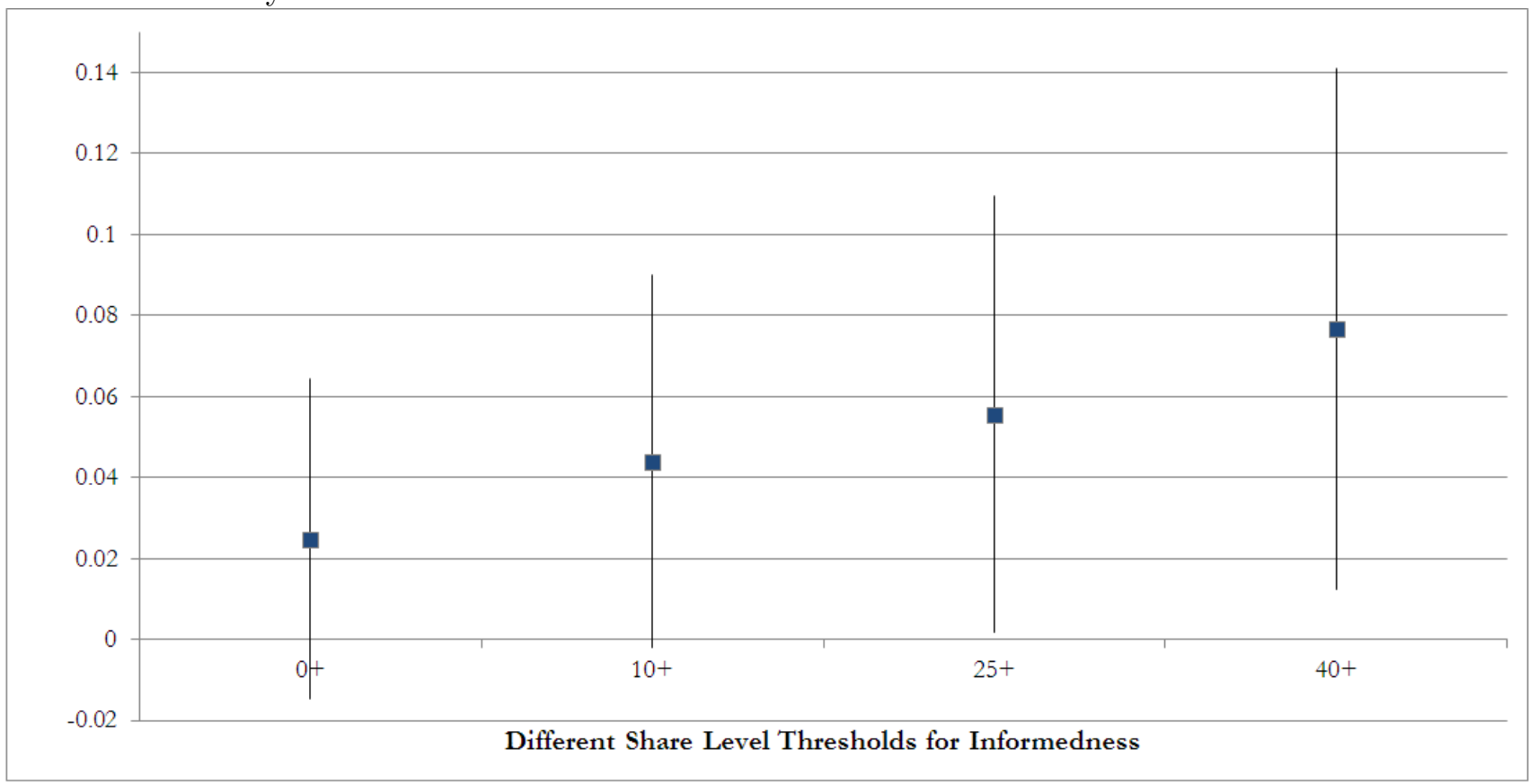

This graph shows the effect of the policy according to different definitions of informativeness. In particular, we create new dummies according to the interfirm relationship a bank observes.

Those relationships where the bank observes two firms with solely overlapping directors has little to no effect on the likelihood a loan is renewed. Whereas if a lender observes two firms with an interfirm relationship where there is a mutual director who owns more than $40 \%$ of the company, those firms' loans are $7.6 \%$ more likely to be renewed than if the lender only observed one of those firms. This is the visual analogue of column 2 in table 8.

The $95 \%$ confidence interval is depicted with the straight lines, and the estimated coefficient is the small blue box. All standard errors are clustered at the level of the component. 
Figure 15. The effect of the policy on the likelihood of a loan being renewed by different number of firm's who borrow from the same bank.

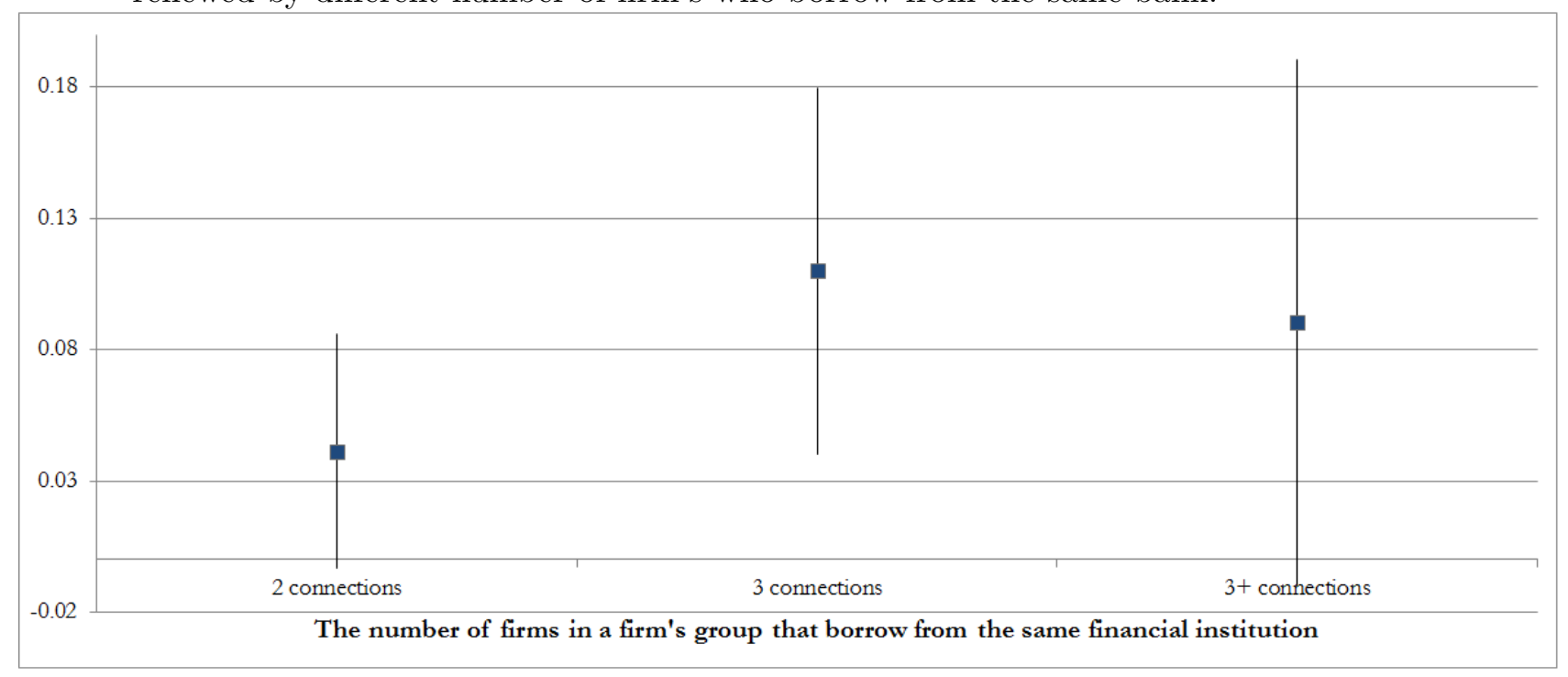

This graph shows as we increase the amount of firms who borrow from the same bank the effects of the policy are greater. This is the visual analogue of column 2 in table 9 , where we are plotting the estimated coefficient and the standard errors from a regression of renewed loan on the number of firm connections borrowing at bank $b$ and the usual three second-order fixed effects. The $95 \%$ confidence interval is depicted with the straight lines, and the estimated coefficient is the small blue box. 
Figure 16. The effect of the policy on the likelihood of a loan being renewed by decile of firm size.

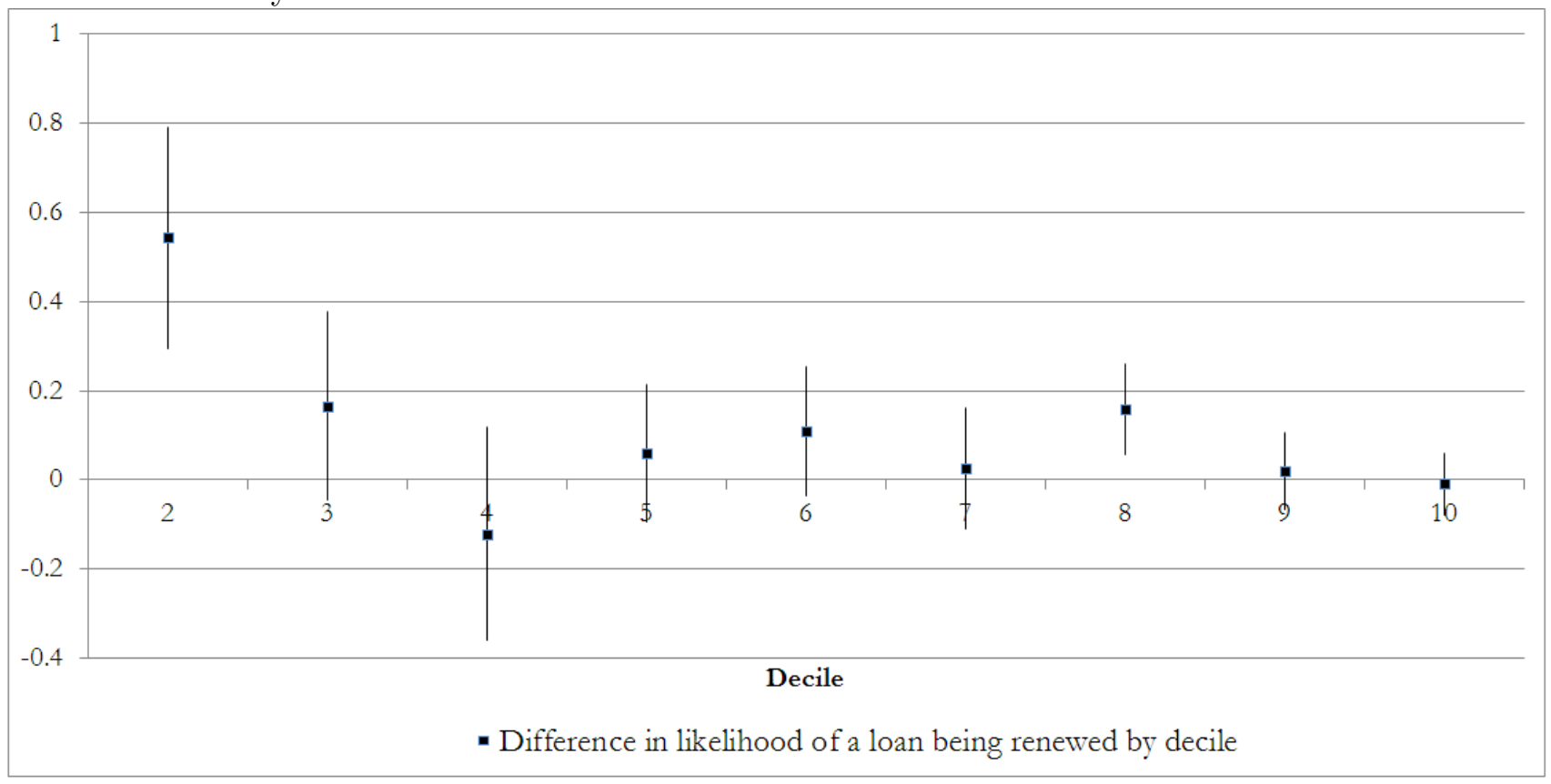

The graph shows the effects were greatest on the smallest firms (using December 2004 total borrowings). This is the visual analogue of column 2 in table 10 where we are plotting the estimated coefficient and the standard errors from a regression of renewed loan on decile (by firm total borrowings in December 2004) interacted with informed loans and the usual three second-order fixed effects.

The deciles are constructed using the total firm borrowings in December 2004, since those firms who borrow small amounts don't have multiple loans, the estimate for the bottom decile is not identified.

The $95 \%$ confidence interval is depicted with the straight lines, and the estimated coefficient is the small blue box. 
FiguRE 17. The effect of the policy on the likelihood of a loan being renewed by decile of group size.

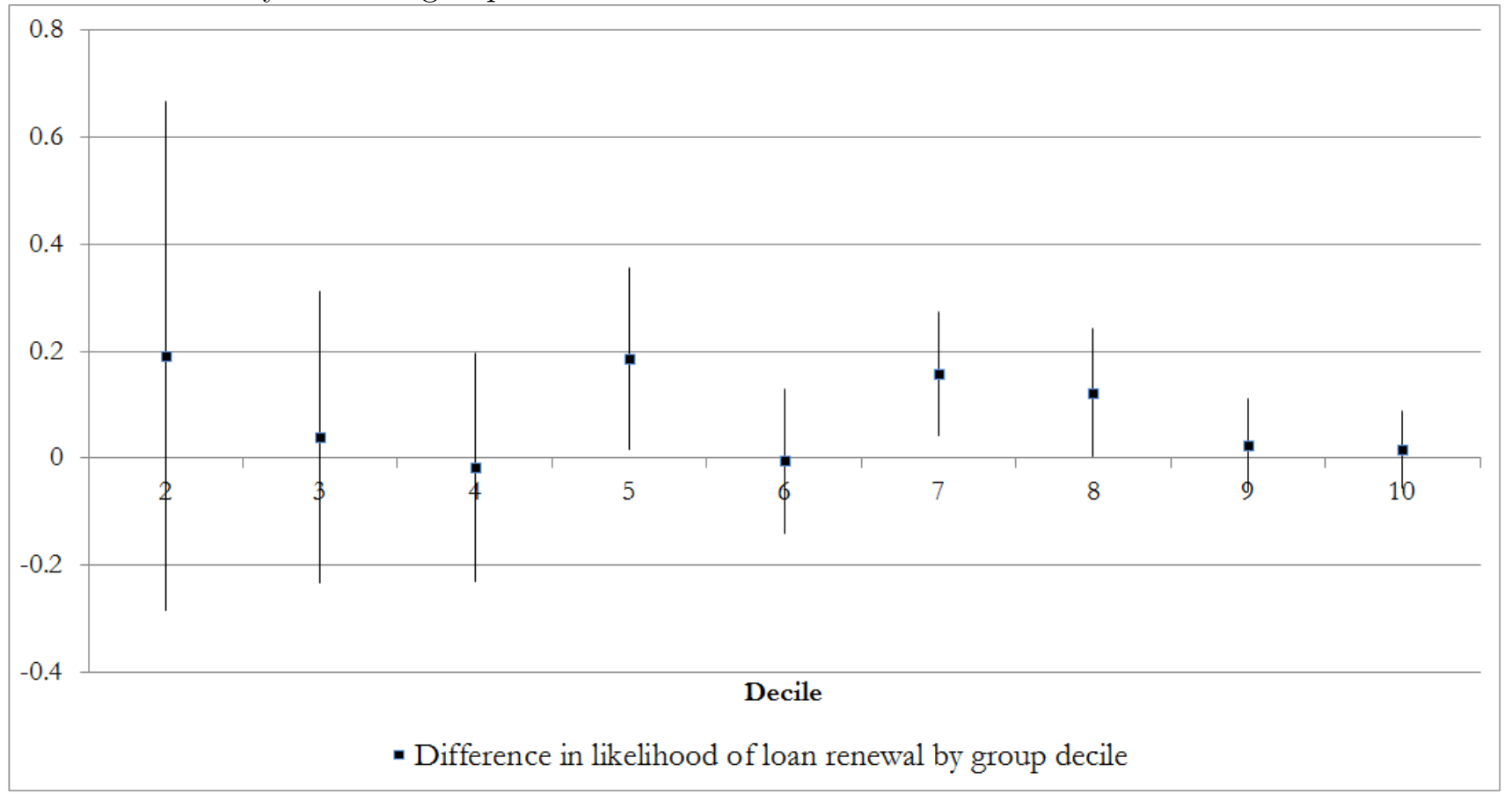

The graph shows the effects were greatest on firms in the smallest groups (using December 2004 total borrowings). This is the visual analogue of column 1 in table 11 , where we are plotting the estimated coefficient and the standard errors from a regression of renewed loan on decile (by group total borrowings in December 2004) interacted with informed loans and the usual three second-order fixed effects. These results suggest that those firms in the very largest groups were unaffected by the policy change. This is consistent with the suggestion that knowledge about the largest groups is already well known in the banking sector.

The deciles are constructed using the total group borrowings in December 2004, since those firms who borrow small amounts don't have multiple loans, the estimate for the bottom decile is not identified.

The $95 \%$ confidence interval is depicted with the straight lines, and the estimated coefficient is the small blue box. Standard errors are clustered at the level of the component. 
FIgURE 18. The monthly coefficients for the difference in total borrowings between borrowers with informed lending relationships and those who do not.

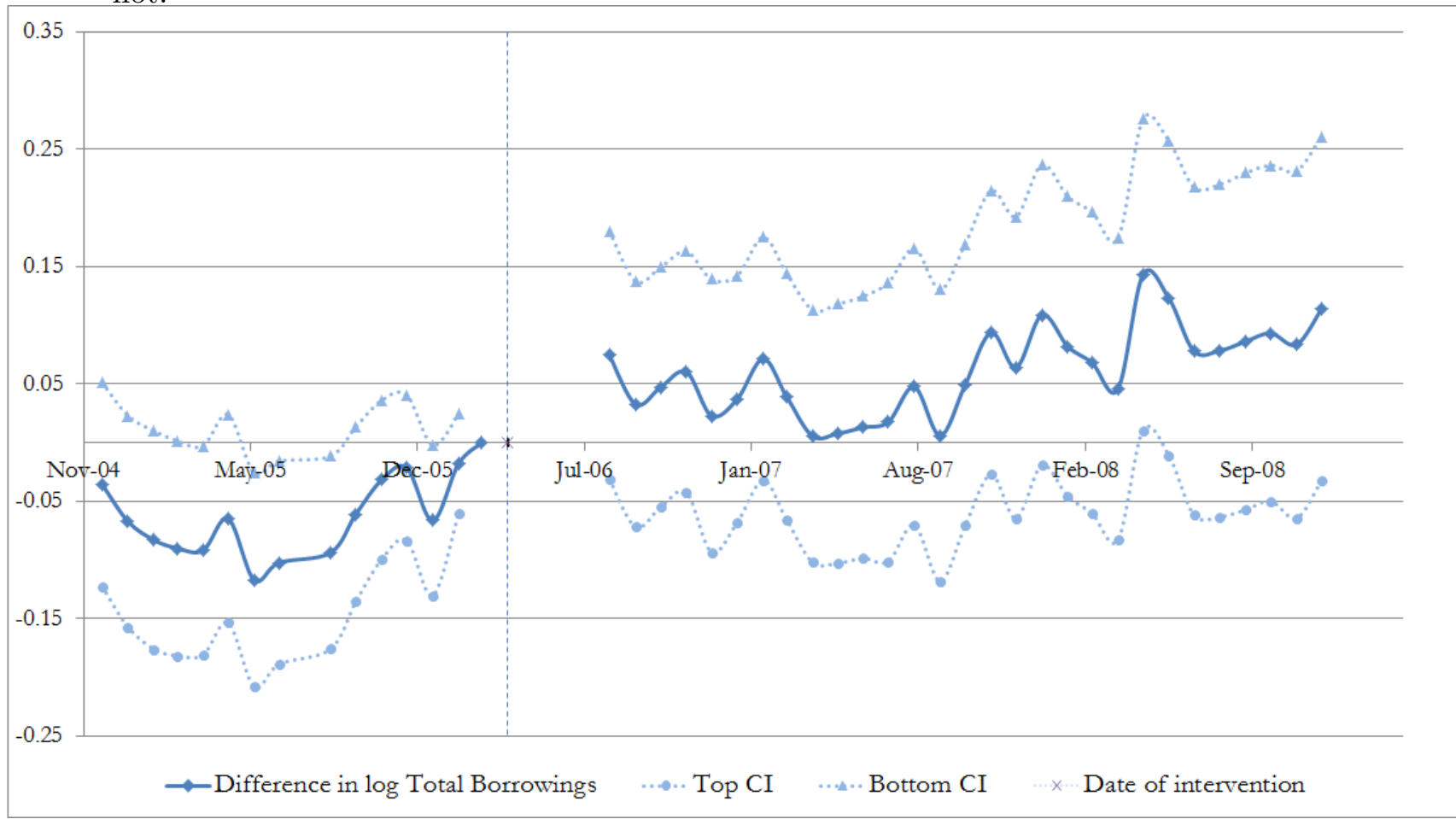

This is the monthly coefficient for informed lender loans, when using 'firm', 'group size specific time trend', 'date FE $\times$ province FE', 'date FE $\times$ business sector FE' controls. The light blue lines are point-wise $95 \%$ confidence intervals. This graph shows that firms with an informed loan were more more likely to receive relatively larger loans following the reform than group firms who did not have a loan from an informed lender. 
FiguRE 19. The effect of the reform on a firm's total borrowings by decile of firm borrowings in December 2004.

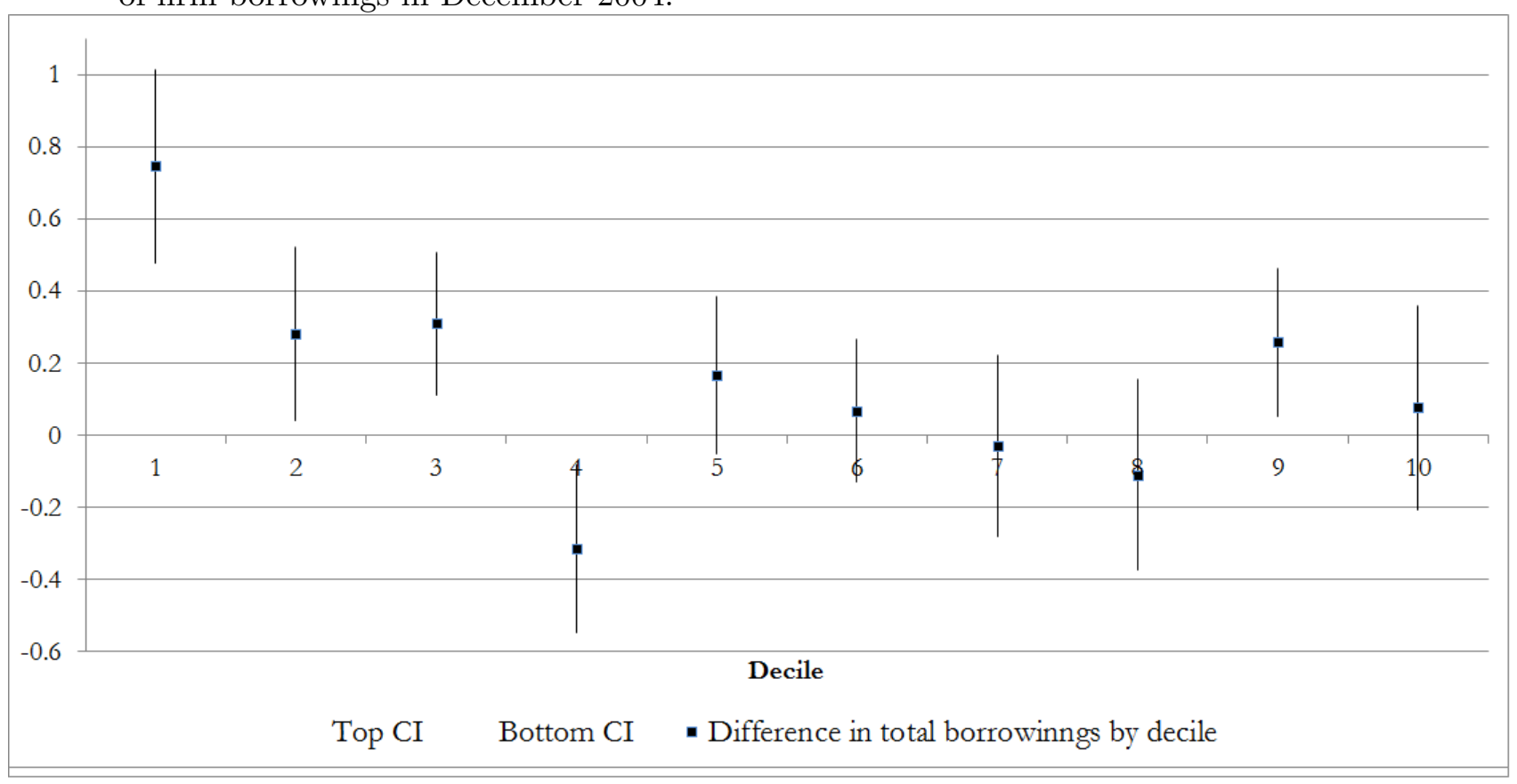

This graph shows the effects were greatest on the smallest firms (using December 2004 total borrowings). This is the visual analogue of column 2 in table 15 , where we are plotting the estimated coefficient and the standard errors from a regression of change in total firm borrowings on an informed lender interacted by each decile (by firm total borrowings in December 2004) and various controls.

The $95 \%$ confidence interval is depicted with the straight lines, and the estimated coefficient is the small blue box. 
TABLE 1. Summary statistics for the entire dataset in December 2004

\begin{tabular}{lcccccc}
\hline & \multicolumn{1}{c}{ Corporate Loans } & \multicolumn{3}{c}{ Consumers and Sole Proprietors } \\
\hline Number of borrowers & \multicolumn{3}{c}{11,395} & \multicolumn{3}{c}{86,053} \\
Percentage of total lending & \multicolumn{3}{c}{$60 \%$} & \multicolumn{3}{c}{$40 \%$} \\
Overdue rates in December 2004 & & $4.50 \%$ & & & & \\
& & & & & \\
& Mean & Median & S.D. & Mean & Median & S.D. \\
Loan size (in '000 Pk. Rupees) & 42,154 & 4,403 & 216,586 & 3,653 & 866 & 28,566 \\
Number of lending partners & 1.73 & 1.00 & 1.79 & 1.06 & 1.00 & 0.29
\end{tabular}

In December 2004, the credit registry maintained details on the entire credit market if a loan was greater than 500,000 Pk. Rupees. The table above demonstrates that largest lending was to corporate firms, and there was a wide dispersion in loan sizes.

TABLE 2. Summary statistics for group firms in December 2004

\begin{tabular}{lcc}
\hline Number of group firms & 3,695 & \\
Number of loans & 7,250 & \\
\hline & Uninformed Loans & Informed Loans \\
\hline Number of loans & 5,867 & 1,383 \\
& Mean & Mean \\
Overdue at baseline & $2.77 \%$ & $2.02 \%$ \\
Loan size (in '000s Pk. Rupees) & 56,343 & 49,791 \\
Log loan size & 9.28 & 9.43 \\
Public banks & $7.0 \%$ & $7.6 \%$ \\
Private domestic commercial bank & $56.5 \%$ & $66.4 \%$ \\
Non-Bank Fin. Corp. (NBFC) & $28.2 \%$ & $17.3 \%$ \\
Foreign bank & $8.3 \%$ & $8.7 \%$
\end{tabular}

A loan is defined at a firm-bank pair. Therefore, if a firm has multiple loans from the same lender, it is classified as a single loan.

An informed loan is defined as a loan where at least two firms in the same group borrow from the same lender. In the following regressions, the paper shows how a firm who has both a informed and uninformed loan respond to the change in information. 
TABLE 3. Summary statistics for group firms who have both an informed and uninformed loan in December 2004

\begin{tabular}{lcc}
\hline Number of group firms & 449 & \\
Number of loans & 1,784 & \\
\hline & Uninformed Loans & Informed Loans \\
\hline Number of loans & 1,035 & 749 \\
& Mean & Mean \\
Overdue at baseline & $1.55 \%$ & $1.33 \%$ \\
Loan size (in '000s Pk. Rupees) & 45,667 & 65,162 \\
Log loan size & 9.18 & 9.55 \\
Public banks & $5.4 \%$ & $5.0 \%$ \\
Private domestic commercial bank & $48.9 \%$ & $63.0 \%$ \\
Non-Bank Fin. Corp. (NBFC) & $37.9 \%$ & $23.1 \%$ \\
Foreign bank & $7.3 \%$ & $8.9 \%$
\end{tabular}

A loan is defined at a firm-bank pair. Therefore, if a firm has multiple loans from the same lender, it is classified as a single loan.

Since the estimation results in section 5 are estimated from firms who have both an informed and uninformed lending relationship, this is the set of firms which identify our main coefficient of interest.

TABLE 4. The effect of the policy on the likelihood of a loan being renewed between informed and uninformed lending relationships

\begin{tabular}{lcccccc}
\hline \hline & $(1)$ & $(2)$ & $(3)$ & $(4)$ & $(5)$ & $(6)$ \\
\hline Informed & 0.00213 & 0.0213 & -0.00830 & & 0.00453 & \\
& $(0.0150)$ & $(0.0135)$ & $(0.0135)$ & & $(0.0126)$ & \\
Post*Informed & $0.0562^{* * *}$ & $0.0734^{* * *}$ & $0.0722^{* * *}$ & $0.0767^{* * *}$ & $0.0517^{* *}$ & $0.0543^{* *}$ \\
& $(0.0121)$ & $(0.0244)$ & $(0.0241)$ & $(0.0242)$ & $(0.0217)$ & $(0.0218)$ \\
\hline Observations & 269625 & 269625 & 269625 & 269625 & 269625 & 269625 \\
Firm\&Date FE & Yes & N/A & N/A & N/A & N/A & N/A \\
Date*Firm FE & No & Yes & Yes & Yes & Yes & Yes \\
Bank FE & Yes & No & Yes & N/A & N/A & N/A \\
Firm*Bank FE & No & No & No & Yes & No & Yes \\
Bank*Date FE & No & No & No & No & Yes & Yes \\
\hline \hline
\end{tabular}

Standard errors in parentheses

${ }^{*} p<0.1,{ }^{* *} p<0.05,{ }^{* * *} p<0.01$

Each regression shows the likelihood of a informed loan to be renewed to be 5-7 pp more likely. All the specifications 2-6 include a date $\times$ firm fixed effect, therefore, we identify the likelihood of a informed loan to be renewed solely from the set of borrowers who have both a informed and uninformed loan. All standard errors are clustered at the level of the component. 
TABLE 5. The effect of the policy on the loan sizes between informed and uninformed lending relationships

\begin{tabular}{lcccccc}
\hline \hline & Loan Size & Loan Size & Loan Size & Loan Size & Loan Size & Loan Size \\
\hline Informed & $0.167^{* *}$ & $0.449^{* * *}$ & $0.216^{* * *}$ & & $0.227^{*}$ & \\
& $(0.0761)$ & $(0.0944)$ & $(0.0728)$ & & $(0.0709)$ & \\
Post*Informed & $0.196^{* * *}$ & 0.111 & 0.120 & 0.125 & 0.0954 & 0.0916 \\
& $(0.0480)$ & $(0.0869)$ & $(0.0854)$ & $(0.0830)$ & $(0.0786)$ & $(0.0775)$ \\
\hline Observations & 269625 & 269625 & 269625 & 269625 & 269625 & 269625 \\
Firm\&Date FE & Yes & N/A & N/A & N/A & N/A & N/A \\
Date*Firm FE & No & Yes & Yes & Yes & Yes & Yes \\
Bank FE & Yes & No & Yes & N/A & N/A & N/A \\
Firm*Bank FE & No & No & No & Yes & No & Yes \\
Bank*Date FE & No & No & No & No & Yes & Yes \\
\hline \hline
\end{tabular}

Standard errors in parentheses

${ }^{*} p<0.1,{ }^{* *} p<0.05,{ }^{* * *} p<0.01$

Each regression shows the likelihood of a informed loan to be to be $9-13 \%$ to be larger following the reform. All the specifications 2-6 include a date $\times$ firm fixed effect, therefore, we identify the difference in loan size solely from the set of borrowers who have both a informed and uninformed loan. All standard errors are clustered at the level of the component.

TABLE 6 . The effect of the policy on the loan sizes between informed and uninformed lending relationships restricting to only those loans that lasted until June 2008 or December 2008.

\begin{tabular}{lcc}
\hline \hline & Loan Size & Loan Size \\
\hline Post*Informed & 0.120 & 0.0698 \\
& $(0.107)$ & $(0.120)$ \\
\hline Observations & 74131 & 74417 \\
Date cutoff & June 2008 & Dec 2008 \\
Date*Firm FE & Yes & Yes \\
Firm*Bank FE & Yes & Yes \\
Bank*Date FE & Yes & Yes \\
\hline \hline
\end{tabular}

Standard errors in parentheses

${ }^{*} p<0.10,{ }^{* *} p<0.05,{ }^{* * *} p<0.01$

This set of regressions restricts attention to only those firm-banks pairs which last until June 2008 or December 2008. The results are very similar to those from table 5, suggesting the effect of the policy is not being driven by firms dropping out of the sample. All standard errors are clustered at the level of the component. 
TABLE 7. The effect of the policy on the loan sizes between informed and uninformed lending relationships - censoring at baseline.

\begin{tabular}{lcccc}
\hline \hline & Loan Renewed & Loan Renewed & Loan Renewed & Loan Renewed \\
\hline Post*Informed & $0.0543^{* *}$ & $0.0495^{* *}$ & 0.0356 & $0.0478^{*}$ \\
& $(0.0218)$ & $(0.0228)$ & $(0.0248)$ & $(0.0267)$ \\
\hline Observations & 269625 & 258814 & 213599 & 181867 \\
Cutoff & $\$ 8500$ & $\$ 12,750$ & $\$ 17,000$ & $\$ 21,250$ \\
Date*Firm FE & Yes & Yes & Yes & Yes \\
Firm*Bank FE & Yes & Yes & Yes & Yes \\
Bank*Date FE & Yes & Yes & Yes & Yes \\
\hline \hline
\end{tabular}

Standard errors in parentheses

${ }^{*} p<0.1,{ }^{* *} p<0.05,{ }^{* * *} p<0.01$

The SBP had a policy of only obliging banks to report a loan's details if the firm's total loan outstanding was greater than 500,000 Rupees $(\$ 8,500)$. This could lead to a bias in our results since loans which were initially just above the cutoff may remain active but partially repaid to be subsequently below 500,000 Rupees and incorrectly categorized as a non-renewed loan. This table omits firms which had a loan amount close to the cutoff in December 2004. Column 1 is the baseline results (Table 4), column 2 omits firms who had a loan outstanding below $\$ 12,750$ in December 2004 (50\% larger than the SBP cutoff), column 3 omits firms who had a loan outstanding below $\$ 17,000$ in December 2004 (100\% larger than the cutoff), and column 4 omits firms who had a loan outstanding below $\$ 21,250$ in December 2004 (150\% larger than the cutoff). All the estimates are similar to those in column 1 suggesting the cutoff is not leading to a noticeable bias in the results. All standard errors are clustered at the level of the component. 
TABLE 8. The effect of greater shareholding on the effect of the policy on loan sizes and likelihood of renewing the loan.

\begin{tabular}{lcc}
\hline \hline & Loan Size & Loan Renewed \\
\hline Post*Informed 0\% & 0.0397 & 0.0248 \\
& $(0.0716)$ & $(0.0202)$ \\
Post*Informed 10\% & 0.0980 & $0.0440^{*}$ \\
& $(0.0936)$ & $(0.0234)$ \\
Post*Informed 25\% & $0.170^{*}$ & $0.0555^{* *}$ \\
& $(0.0993)$ & $(0.0275)$ \\
Post*Informed 40\% & 0.0218 & $0.0767^{* *}$ \\
& $(0.122)$ & $(0.0328)$ \\
\hline Observations & 269625 & 269625 \\
Date*Firm FE & Yes & Yes \\
Firm*Bank FE & Yes & Yes \\
Bank*Date FE & Yes & Yes \\
\hline \hline Standard errors in parentheses & \\
${ }^{*} p<0.1,{ }^{* *} p<0.05,{ }^{* * *} p<0.01$ &
\end{tabular}

Construction of the 'informed 40\%' variable is the same as the procedure in the paper for constructing the benchmark bank-firm pairs, except using a $40 \%$ cutoff for directorial shareholding. We construct the 'informed 25\%' variable to be those firm-bank pairs who would be defined as informed using the usual definition with a $25 \%$ director shareholder cutoff except omitting those firm-bank pairs that were already labeled as 'informed 40\%'. A similar procedure is used to construct the $10 \%$ and $0 \%$ informed variables. All standard errors are clustered at the level of the component. 
TABLE 9. The effect of the greater number of firms borrowing from the same institution on loan sizes and likelihood of renewing the loan.

\begin{tabular}{lcc}
\hline \hline & Loan Size & Loan Renewed \\
\hline Post*2 Informed firms & 0.0554 & $0.0431^{*}$ \\
& $(0.0804)$ & $(0.0228)$ \\
Post*3 Informed firms & 0.212 & $0.111^{* * *}$ \\
& $(0.143)$ & $(0.0356)$ \\
Post*3+ Informed firms & $0.446^{*}$ & $0.0913^{*}$ \\
& $(0.229)$ & $(0.0511)$ \\
\hline Observations & 269625 & 269625 \\
Date*Firm FE & Yes & Yes \\
Firm*Bank FE & Yes & Yes \\
Bank*Date FE & Yes & Yes \\
\hline \hline Standard errors in parentheses & \\
${ }^{*} p<0.1,{ }^{* *} p<0.05,{ }^{* * *} p<0.01$ &
\end{tabular}

Construction of the '\# informed firms' variable is done through adding the total number of firms in a firm's group who borrow from the same lender. Therefore, these regressions suggest a bank was more willing to renew a loan, the greater the number of group firms the lender lent to in December 2004. All standard errors are clustered at the level of the component. 
TABLE 10. The effect of the policy by decile of firm size

\begin{tabular}{|c|c|c|}
\hline & L Loan Size & L Loan Renewed \\
\hline Post*Informed*2nd Decile by Firm Size & $\begin{array}{l}0.461^{* *} \\
(0.232)\end{array}$ & $\begin{array}{c}0.543^{* * *} \\
(0.127)\end{array}$ \\
\hline Post*Informed*3rd Decile by Firm Size & $\begin{array}{c}0.247 \\
(0.242)\end{array}$ & $\begin{array}{c}0.166 \\
(0.108)\end{array}$ \\
\hline Post*Informed*4th Decile by Firm Size & $\begin{array}{r}-0.0207 \\
(0.207)\end{array}$ & $\begin{array}{l}-0.122 \\
(0.122)\end{array}$ \\
\hline Post*Informed*5th Decile by Firm Size & $\begin{array}{c}0.112 \\
(0.212)\end{array}$ & $\begin{array}{c}0.0607 \\
(0.0783)\end{array}$ \\
\hline Post*Informed*6th Decile by Firm Size & $\begin{array}{c}0.356 \\
(0.211)\end{array}$ & $\begin{array}{c}0.109 \\
(0.0738)\end{array}$ \\
\hline Post*Informed*7th Decile by Firm Size & $\begin{array}{l}0.0125 \\
(0.215)\end{array}$ & $\begin{array}{c}0.0262 \\
(0.0686)\end{array}$ \\
\hline Post*Informed*8th Decile by Firm Size & $\begin{array}{c}0.134 \\
(0.146)\end{array}$ & $\begin{array}{l}0.158^{* * *} \\
(0.0519)\end{array}$ \\
\hline Post*Informed $* 9$ th Decile by Firm Size & $\begin{array}{c}0.102 \\
(0.174)\end{array}$ & $\begin{array}{c}0.0225 \\
(0.0446)\end{array}$ \\
\hline Post*Informed*10th Decile by Firm Size & $\begin{array}{c}-0.00955 \\
(0.152)\end{array}$ & $\begin{array}{r}-0.00843 \\
(0.0355)\end{array}$ \\
\hline Observations & 269625 & 269625 \\
\hline Date*Firm FE & Yes & Yes \\
\hline Firm*Bank FE & Yes & Yes \\
\hline Bank*Date FE & Yes & Yes \\
\hline
\end{tabular}

Each decile is constructed by computing the total firm borrowings in December 2004. The effect on the smallest decile is not identified in the data since the smallest borrowers in December 2004 only had one loan and the identification relies on a borrower having at least two loans. All standard errors are clustered at the level of the component. The results for column 2 are shown in figure 16 . 
PUBLIC INFORMATION AND ASYMMETRICALLY INFORMED LENDERS

TABLE 11. The effect of the policy by decile of group size

\begin{tabular}{lcc}
\hline \hline & Loan Renewed & Loan Size \\
\hline Post*Informed*2nd Decile by Group Size & 0.191 & -0.112 \\
& $(0.242)$ & $(0.397)$ \\
Post*Informed*3rd Decile by Group Size & 0.0394 & -0.158 \\
& $(0.139)$ & $(0.227)$ \\
Post*Informed*4th Decile by Group Size & -0.0168 & -0.106 \\
& $(0.109)$ & $(0.252)$ \\
Post*Informed*5th Decile by Group Size & $0.187^{* *}$ & $0.460^{* * *}$ \\
& $(0.0864)$ & $(0.164)$ \\
Post*Informed*6th Decile by Group Size & -0.00495 & 0.0781 \\
& $(0.0690)$ & $(0.214)$ \\
Post*Informed*7th Decile by Group Size & $0.158^{* * *}$ & 0.0999 \\
& $(0.0589)$ & $(0.195)$ \\
Post*Informed*8th Decile by Group Size & $0.123^{* *}$ & $0.297^{*}$ \\
& $(0.0605)$ & $(0.177)$ \\
Post*Informed*9th Decile by Group Size & 0.0249 & -0.0769 \\
& $(0.0438)$ & $(0.159)$ \\
Post*Informed*10th Decile by Group Size & 0.0155 & 0.0967 \\
& $(0.0368)$ & $(0.152)$ \\
\hline Observations & 269625 & 269625 \\
Date*Firm FE & Yes & Yes \\
Firm*Bank FE & Yes & Yes \\
Bank*Date FE & Yes & Yes \\
\hline \hline
\end{tabular}

Standard errors in parentheses

${ }^{*} p<0.1,{ }^{* *} p<0.05,{ }^{* * *} p<0.01$

Each decile is constructed by computing the total group borrowings in December 2004. The effect on the smallest decile is not identified in the data since the smallest borrowers in December 2004 only had one loan and the identification relies on a borrower having at least two loans. The results show that the effect of the reform was largest on those firms who belonged to the smallest group. This is consistent with the view that there is common knowledge about a firm's group for the very largest groups.

All standard errors are clustered at the level of the component. The results for column 2 are shown in figure 17. 
TABLE 12. Firms who were overdue at baseline were more likely to renew their informed loan.

\begin{tabular}{lcc}
\hline \hline & Loan Size & Loan Renewed \\
\hline Post*Informed & 0.0681 & $0.0477^{* *}$ \\
& $(0.0778)$ & $(0.0222)$ \\
Post*Informed*Firm Overdue & $0.472^{*}$ & $0.133^{*}$ \\
& $(0.278)$ & $(0.0691)$ \\
\hline Observations & 269625 & 269625 \\
Date*Firm FE & Yes & Yes \\
Firm*Bank FE & Yes & Yes \\
Bank*Date FE & Yes & Yes \\
\hline \hline
\end{tabular}

\footnotetext{
Standard errors in parentheses

${ }^{*} p<0.1,{ }^{* *} p<0.05,{ }^{* * *} p<0.01$
}

This is suggestive evidence that those firms who had been overdue in the past were more likely to renew their loans at an informed banking relationships. This suggests that those firms for may be classified as the most risky were also the ones most likely to have their loans renewed by an informed lender. All standard errors are clustered at the level of the component.

TABLE 13. The difference in the likelihood of a loan going overdue

\begin{tabular}{lcc}
\hline \hline & Overdue & Overdue \\
\hline Informed & $0.0163^{* * *}$ & \\
& $(0.00518)$ & \\
Post*Informed & $-0.0287^{* * *}$ & -0.00719 \\
& $(0.00666)$ & $(0.0141)$ \\
\hline Observations & 209962 & 209962 \\
Firm\&Date FE & Yes & N/A \\
Date*Firm FE & No & Yes \\
Bank FE & Yes & N/A \\
Firm*Bank FE & No & Yes \\
Bank*Date FE & No & Yes \\
\hline \hline Standard errors in parentheses & \\
${ }^{*} p<0.1,{ }^{* *} p<0.05,{ }^{* * *} p<0.01$ &
\end{tabular}

Caution should be taken when taking inference from these regressions. As described in the text, this is not estimating the causal impact of the regulation change on the likelihood of a loan becoming overdue, since in table 4 , we showed uninformed loans were more likely to be not renewed. Column 1 does not include firm interacted with date fixed effects. Therefore, column 1 suggests the loans that were renewed by uninformed lenders were more likely to default. Column 2 which includes the firm interacted with date fixed effect suggests that those firms for whom the informed and uninformed lender renewed, there was no differential in default.

All standard errors are clustered at the level of the component. 
TABLE 14. Difference in total loan sizes between firms who have an informed lender and those who do not.

\begin{tabular}{lcccc}
\hline \hline & Total Loans & Total Loans & Total Loans & Total Loans \\
\hline Post*Informed lender & $0.130^{* * *}$ & $0.134^{* * *}$ & $0.113^{* *}$ & $0.123^{* *}$ \\
& $(0.0447)$ & $(0.0458)$ & $(0.0464)$ & $(0.0476)$ \\
Constant & $9.845^{* * *}$ & & & \\
& $(0.0470)$ & & & \\
\hline Observations & 161744 & 155496 & 149248 & 145684 \\
Firm FE & Yes & Yes & Yes & Yes \\
Date FE & Yes & N/A & N/A & N/A \\
Group Size Specific Time Trend & Yes & Yes & Yes & Yes \\
Business Sector FE*Date FE & No & Yes & No & Yes \\
Province FE*Date FE & No & No & Yes & Yes \\
\hline \hline Standard errors in parentheses & & & & \\
${ }^{*} p<0.10,{ }^{* *} p<0.05,{ }^{* * *} p<0.01$ & & & &
\end{tabular}

The difference-in-difference estimates suggest that those firms with an informed lender were able to borrow $11 \%-14 \%$ more following the reform than those firms with no informed lender. Column 1 shows the estimates with firm fixed effects and a group size specific time trend. Column 2 shows the estimates when including business sector interacted with date fixed effects. Column 3 shows the estimates when including province interacted with date fixed effects. Lastly column 4 shows the estimates where we include all interacted fixed effects. We are missing the data on the province and business sector for a small fraction of the firms, therefore, they are omitted from those regressions which include province or business sector fixed effects. All standard errors are clustered at the level of the component. 
TABLE 15. The difference in total loan borrowings by firm decile and whether they had an informed lending relationship.

\begin{tabular}{|c|c|c|}
\hline & Total Loans & Total Loans \\
\hline \multirow[t]{2}{*}{ Post*Informed*1st Decile } & $0.764^{* * *}$ & $0.756^{* * *}$ \\
\hline & $(0.118)$ & $(0.137)$ \\
\hline \multirow{2}{*}{ Post*Informed*2nd Decile } & $0.253^{* *}$ & $0.290^{* *}$ \\
\hline & $(0.103)$ & $(0.121)$ \\
\hline \multirow[t]{2}{*}{ Post*Informed*3rd Decile } & $0.310^{* * *}$ & $0.318^{* * *}$ \\
\hline & $(0.0957)$ & $(0.101)$ \\
\hline \multirow[t]{2}{*}{ Post*Informed*4th Decile } & $-0.274^{* * *}$ & $-0.311^{* * *}$ \\
\hline & $(0.104)$ & $(0.119)$ \\
\hline \multirow[t]{2}{*}{ Post*Informed*5th Decile } & $0.217^{* *}$ & 0.173 \\
\hline & $(0.102)$ & $(0.111)$ \\
\hline \multirow[t]{2}{*}{ Post*Informed*6th Decile } & 0.0678 & 0.0708 \\
\hline & $(0.0988)$ & $(0.101)$ \\
\hline \multirow[t]{2}{*}{ Post*Informed*7th Decile } & -0.0511 & -0.0282 \\
\hline & $(0.129)$ & $(0.128)$ \\
\hline \multirow[t]{2}{*}{ Post*Informed*8th Decile } & -0.0714 & -0.100 \\
\hline & $(0.134)$ & $(0.136)$ \\
\hline \multirow[t]{2}{*}{ Post*Informed*9th Decile } & $0.267^{* *}$ & $0.257^{* *}$ \\
\hline & $(0.105)$ & $(0.105)$ \\
\hline \multirow[t]{2}{*}{ Post*Informed*10th Decile } & 0.0340 & 0.0728 \\
\hline & $(0.132)$ & $(0.143)$ \\
\hline \multirow[t]{2}{*}{ Constant } & $9.845^{* * *}$ & \\
\hline & $(0.0458)$ & \\
\hline Observations & 161744 & 145684 \\
\hline Firm FE & Yes & Yes \\
\hline Date FE & Yes & $\mathrm{N} / \mathrm{A}$ \\
\hline Group Size Specific Time Trend & Yes & Yes \\
\hline Business Sector*Date FE & No & Yes \\
\hline Province*Date FE & No & Yes \\
\hline
\end{tabular}

Standard errors in parentheses

${ }^{*} p<0.10,{ }^{* *} p<0.05,{ }^{* * *} p<0.01$

These regressions interact a dummy variable for each decile (by total firm borrowings in December 2004) with the post $\times$ informed lender variable. Hence, we are estimating the effect of the policy separately for each decile. The estimates suggest that the largest effects were on the smallest firms, which is similar to the results shown in section 5.2.3. Figure 19 plots the results in column 2. All standard errors are clustered at the level of the component. 


\section{APPENDIX}

9.1. Proof of Proposition 1. A Perfect Bayesian Equilibrium of the game is:

$$
\begin{aligned}
\text { (informed lender) } k_{I}^{L} & =0, k_{I}^{H}=k_{I}^{H *}>0 \\
\text { (uninformed lender) } k_{N} & =k_{N}^{*} \geq 0 \\
\left(\text { firm) } s_{f}^{i}\right. & =(\text { Acc }, \text { Acc })
\end{aligned}
$$

Proof. To prove the exist a PBE we will first solve for the firm's weakly dominant strategy, and then we shall proceed to solve for the PBE under different parameter values.

To solve for the firm's weakly dominant strategy recall the firm's utility function:

$$
U_{i}(k, R)=\frac{X_{i}}{1+k}(A-R) k
$$

The firm's utility function is strictly increasing in capital, $k$, for all non-negative $k$ since we assume the productivity parameter $A$ is strictly greater than the interest rate $R$. Therefore, the firm's weakly dominant strategy is to accept all loan offers from both lenders.

Now let us consider the informed lender's optimal strategy if the uninformed lender is offering $k_{N}$ and the firm accepts all loan offers. The informed lender wishes to maximise:

$$
\pi_{I}^{i}\left(k_{I}^{i}, k_{N}, X_{i}\right)=\max \left[\frac{X_{i}}{1+k_{I}^{i}+k_{N}} R-\rho\right] k_{I}^{i}
$$

Since we assumed that $\frac{R X_{L}}{\rho}<1$, we know that the informed lender's strictly dominant strategy having observed a low borrower type will be $k_{I}^{L}=0$ since expected profits will always be strictly negative if she ever offers a non-zero loan size.

Now let us consider the case where the informed lender observes a high borrower type and let us assume that the following condition holds:

$$
\gamma\left(\frac{R X_{L}}{\rho}\right)+(1-\gamma)\left(\frac{R X_{H}}{\rho}\right)^{0.5}<1
$$

Then there exists a PBE:

$$
\begin{aligned}
\text { (informed lender) } k_{I}^{L^{*}} & =0, k_{I}^{H^{*}}=k_{H}^{\max }=\left(\frac{R X_{H}}{\rho}\right)^{0.5}-1>0 \\
\text { (uninformed lender) } k_{N}^{*} & =0 \\
\left(\text { firm) } s_{f}^{i}\right. & =(\text { Acc }, \text { Acc })
\end{aligned}
$$


To verify this is a PBE, the informed lender's marginal profit condition is:

$$
\frac{\partial \pi}{\partial k_{I}}=R X_{H} \frac{\left(1+k_{N}\right)}{\left(1+k_{N}+k_{I}^{H}\right)^{2}}-\rho=0
$$

And since the profit function is concave in $k_{I}^{i}$ the local maximum is sufficient for the lenders' optimal strategy given the other lender's strategy. If the uninformed lender chooses $k_{N}=0$, then the solution to equation 3 is $k_{I}^{H}=k_{H}^{\max }$. To check this is a PBE, we need to check the uninformed lender's optimal strategy.

The marginal profit condition for the uninformed lender is:

$$
\frac{\partial \pi}{\partial k_{N}}=\gamma R X_{L} \frac{1}{\left(1+k_{N}\right)^{2}}+(1-\gamma) R X_{H} \frac{\left(1+k_{I}^{H}\right)}{\left(1+k_{N}+k_{I}^{H}\right)^{2}}-\rho
$$

If we substitute in the conjectured optimal informed lender's strategy, this becomes:

$$
\left.\frac{\partial \pi}{\partial k_{N}}\right|_{k_{H}=k_{H}^{\max }}=\gamma R X_{L} \frac{1}{\left(1+k_{N}\right)^{2}}+(1-\gamma) R X_{H} \frac{\left(\frac{R X_{H}}{\rho}\right)^{0.5}}{\left(k_{N}+\left(\frac{R X_{H}}{\rho}\right)^{0.5}\right)^{2}}-\rho
$$

Similar to the informed lender's problem, the uninformed lender's profit is concave in $k_{N}$. Therefore, if we can show the uninformed lender's marginal profit is negative at $k_{N}=0$ we know the uninformed lender's optimal strategy given the informed lender's strategy is to offer $k_{N}=0$.

Plugging in $k_{N}=0$ into equation 4 gives:

$$
\left.\frac{\partial \pi}{\partial k_{N}}\right|_{k_{N}=0, k_{H}=k_{H}^{\max }}=\gamma R X_{L}+(1-\gamma) R X_{H}^{0.5}-\rho
$$

Using the assumption in equation 2, we know this is strictly less than zero. Therefore, the uninformed lender's optimal strategy given the informed lender's strategy is to offer $k_{N}=0$.

To complete the proof for all feasible values of $X_{H}$ and $X_{L}$ we will solve the uninformed and informed lender's maximization problems assuming the constraints that each lender does not have a negative loan size or a negative expected profits do not bind. We will then show for those parameter values where the constraints do bind the equilibrium will be such that $k_{N}^{*}=0, k_{I}^{L^{*}}=0, k_{I}^{H^{*}}=k_{I}^{\max }$.

Recall the informed lender's marginal profit condition: 


$$
\frac{\partial \pi}{\partial k_{I}}=R X_{H} \frac{\left(1+k_{N}\right)}{\left(1+k_{N}+k_{I}^{H}\right)^{2}}-\rho
$$

Recall the uninformed lender's marginal profit condition:

$$
\frac{\partial \pi}{\partial k_{N}}=\gamma R X_{L} \frac{1}{\left(1+k_{N}\right)^{2}}+(1-\gamma) R X_{H} \frac{\left(1+k_{I}^{H}\right)}{\left(1+k_{N}+k_{I}^{H}\right)^{2}}-\rho
$$

Assuming no constraints bind, we can set equations 5 and 6 equal to zero and solve for $k_{I}^{H}$ and $k_{N}$ as a function of the parameters (the first order conditions are sufficient since both lenders' profits are concave in their respective capital offers). First we show that the solution of these two equations imply that $k_{I}^{H^{*}}>0$.

To reduce notation let us define $Y \equiv 1+k_{N}, Z_{H} \equiv \frac{R X_{H}}{\rho}$ and $Z_{L} \equiv \frac{R X_{L}}{\rho}$.

Then we can rewrite the two marginal profit conditions (FOCs) as:

$$
\begin{aligned}
Z_{H} Y & =\left(k_{I}+Y\right)^{2} \\
\gamma Z_{L} \frac{1}{Y^{2}}+(1-\gamma) Z_{H} \frac{\left(1+k_{I}^{H}\right)}{\left(k_{I}^{H}+Y\right)^{2}} & =1
\end{aligned}
$$

Plugging in $\left(k_{I}+Y\right)^{2}$ from equation 7 into equation 8 . We have the equation:

$$
\gamma Z_{L} \frac{1}{Y^{2}}+(1-\gamma) Z_{H} \frac{\left(1+k_{I}^{H}\right)}{Z_{H} Y}=1
$$

Simplifying and rearranging equation 9

$$
Y^{2}-(1-\gamma)\left(1+k_{I}^{H}\right) Y-\gamma Z_{L}=0
$$

Solving for $Y$ :

$$
Y=\frac{(1-\gamma)\left(1+k_{I}^{H}\right) \pm \sqrt{(1-\gamma)^{2}\left(1+k_{I}^{H}\right)^{2}+4 \gamma Z_{L}}}{2}
$$

We are interested in $k_{N}>0$ (the maximum), so we can restrict ourselves to the positive root of $Y$.

Rearranging equation 7 ; 


$$
Y^{2}+\left(2 k_{I}^{H}-Z_{H}\right) Y+\left(k_{I}^{H}\right)^{2}=0
$$

Subtracting 10 from 12 gives:

$$
\left(2 k_{I}^{H}-Z_{H}+(1-\gamma)\left(1+k_{I}\right)\right) Y+\left(k_{I}^{H}\right)^{2}+\gamma Z_{L}=0
$$

We can substitute $Y$ from equation 11 into 13 . Equation 13 is continuous in $k_{I}^{H}$, the left hand size of 13 is less than zero if $k_{I}^{H}=0$, and the left hand side of 13 tends to infinity as $k_{I}^{H}$ goes to infinity, therefore there must exist a positive $k_{I}^{H}$ such that both FOCs are satisfied. Since, there exists a $k_{I}^{H}$ which satisfy the two FOCs, then there must also exist a corresponding $k_{N}$.

However, the choice of $k_{N}$, which satisfies the FOC may not be feasible. In particular, at those parameter values $k_{N}$ may be less than zero. We now show that $k_{N}$ is always greater than zero from the FOC conditions.

Recall equation 11 .

$$
Y=\frac{(1-\gamma)\left(1+k_{I}^{H}\right) \pm \sqrt{(1-\gamma)^{2}\left(1+k_{I}^{H}\right)^{2}+4 \gamma Z_{L}}}{2}
$$

We want to show that $Y \equiv 1+k_{N}$ is always greater than one. Since, $Y$ is increasing in $k_{I}^{H}$, and we have shown $k_{I}^{H}$ is always greater than zero, then if we show this equation holds when $k_{I}^{H}=0$, it must hold for all parameter values. Therefore:

$$
Y=\frac{(1-\gamma)\left(1+k_{I}^{H}\right)+\sqrt{(1-\gamma)^{2}\left(1+k_{I}^{H}\right)^{2}+4 \gamma Z_{L}}}{2}>1
$$

Substituting in $k_{I}^{H}=0$ and rearranging, we obtain:

$$
\sqrt{(1-\gamma)^{2}+4 \gamma Z_{L}}>(1+\gamma)
$$

Square both sides (both sides are positive) and rearrange:

$$
Z_{L}>\frac{1}{2}
$$

From our assumptions on the parameter space, this is always true. Therefore both the $k_{I}^{H}$ and $k_{N}$ that satisfy the two FOCs are greater than zero.

Finally to complete the proof, we must show what happens when the uninformed lender's profit condition is not satisfied. We need the following preliminaries: (i) the informed 
lender's best response function is decreasing in $k_{N}$ for all feasible values of $k_{N}$, (ii) the uninformed lender's best response function is decreasing in $k_{I}^{H}$ and (iii) in equilibrium $k_{I}^{H}>k_{N}$.

Proof of preliminary (i)

Totally differentiating equation 5 with respect to $k_{N}$ and rearranging:

$$
\frac{d k_{I}^{H}}{d k_{N}}=\frac{Z_{H}^{0.5}}{2\left(1+k_{N}\right)^{0.5}}-1<0
$$

Therefore, the optimal $k_{I}^{H}$ is decreasing for all non-negative values of $k_{N}$ since we assumed $Z_{H}<4$.

Proof of preliminary (ii)

Totally differentiating the uninformed lender's FOC condition (equation 8) with respect to $k_{I}^{H}$ gives:

$$
-2 \gamma Z_{L} \frac{1}{Y^{3}} \frac{d Y}{d k_{I}^{H}}+\frac{(1-\gamma) Z_{H}}{\left(k_{I}^{H}+Y\right)^{4}}\left[\left(k_{I}^{H}+Y\right)^{2}-2\left(1+\frac{d Y}{d k_{I}^{H}}\right)\left(k_{I}^{H}+Y\right)\left(1+k_{I}^{H}\right)\right]=0
$$

Rearranging and simplifying:

$$
\begin{aligned}
\frac{d Y}{d k_{I}^{H}} & =\left(k_{I}^{H}+Y\right)^{2}-2\left(k_{I}^{H}+Y\right)\left(1+k_{I}^{H}\right) \\
\frac{d k_{N}}{d k_{I}^{H}} & =\left(k_{I}^{H}+Y\right)\left(k_{N}-1-k_{I}^{H}\right)
\end{aligned}
$$

Therefore, if $k_{I}^{H}$ is greater than $k_{N}$ then the uninformed lender's choice of $k_{N}$ is decreasing in $k_{I}^{H}$.

Proof of preliminary (iii)

Follows from the proof of proposition 2

Therefore, now we have shown that $k_{N}$ is decreasing in $k_{I}^{H}$, and $k_{I}^{H}$ is decreasing in $k_{N}$. We know if the FOC suggest a solution with negative expected profits for the uninformed lender, the uninformed lender will always set $k_{N}=0$. This follows from (i) the informed lender's optimal response will be to increase her choice of $k_{I}^{H}$ if the uninformed lender's choice of $k_{N}$ decreases, and (ii) if the informed lender's choice of $k_{I}^{H}$ increases, the uninformed lender will always wish to decrease her choice of $k_{N}$ - ultimately, this leads to $k_{N}=0$. 
Finally, we need to check the informed lenders expected profits are always greater than zero. There are two cases: (i) if the uninformed lender offers a positive loan size and (ii) the uninformed lender does not enter.

Case (i):

If the uninformed lender has a positive loan size then the following condition must hold:

$$
R X_{H} \frac{1}{\left(1+k_{N}^{*}+k_{I}^{H^{*}}\right)^{2}}-\rho \geq 0
$$

Recalling the informed lender's profit function:

$$
E\left[\pi_{I}^{H}\left(k_{I}^{H^{*}}, k_{N}\right)\right]=R X_{H} \frac{k_{I}^{H^{*}}}{\left(1+k_{N}^{*}+k_{I}^{H^{*}}\right)^{2}}-\rho k_{I}^{H^{*}}
$$

If equation 15 is satisfied then the informed lender's profits must be greater than zero.

Case (ii):

The informed lender profits must similarly be greater than zero since $\frac{R X_{H}}{\rho}$ is assumed to be greater than 1, therefore, the informed lender can always make a positive profit.

To sum, we have shown there exists a solution to first order conditions when we do not restrict profits to be non-negative or loan size to be positive. Then we have shown a PBE there exists a PBE for those parameter values such that the first order conditions give a non-feasible solution.

Further, it can be shown there is no mixed strategy PBE in this model.

9.2. Proof of Proposition 2, The informed lender will lend more in expectation than the uninformed lender:

$$
\Delta \equiv(1-\gamma) k_{I}^{H^{*}}-k_{N}^{*}>0
$$

Proof. There are two possible cases, (i) $k_{N}^{*}=0$ and (ii) $k_{N}^{*}>0$.

Case (i): $k_{N}^{*}=0$

Consider the informed lender's FOC:

$$
R X_{H} \frac{\left(1+k_{N}\right)}{\left(1+k_{N}+k_{I}^{H}\right)^{2}}-\rho=0
$$

Using $k_{N}^{*}=0$ and the assumption that $\frac{R X_{H}}{\rho}>1$ (that it is profitable to offer loans to the high type), then the equilibrium $k_{I}^{H^{*}}>0$ and $\pi_{I}^{*}>0$. It follows $\Delta>0$. 
Case (ii): $k_{N}^{*}>0$

In this situation both the lenders' FOCs must hold. We will first solve for the equilibrium $k_{I}^{*}$ and $k_{N}^{*}$ which satisfy the two FOCs, and then using a proof by contradiction we will show that $(1-\gamma) k_{I}^{*}-k_{N}^{*}>0$.

To reduce notation let us define $Y \equiv 1+k_{N}, Z_{H} \equiv \frac{R X_{H}}{\rho}$ and $Z_{L} \equiv \frac{R X_{L}}{\rho}$.

Recall equation 11

$$
Y=\frac{(1-\gamma)\left(1+k_{I}\right) \pm \sqrt{(1-\gamma)^{2}\left(1+k_{I}\right)^{2}+4 \gamma Z_{L}}}{2}
$$

We are interested in $k_{N}>0$ (the maximum), so we can restrict ourselves to the positive root of $Y$.

We want to show that $\Delta \equiv(1-\gamma) k_{I}-k_{N} \equiv 1+(1-\gamma) k_{I}-Y>0$. We will complete the proof by contradiction. Assume $\Delta \leq 0$ then:

$$
\begin{aligned}
1+(1-\gamma) k_{I} & \leq Y \\
1+(1-\gamma) k_{I} & \leq \frac{(1-\gamma)\left(1+k_{I}\right) \pm \sqrt{(1-\gamma)^{2}\left(1+k_{I}\right)^{2}+4 \gamma Z_{L}}}{2}
\end{aligned}
$$

In equation 18 we have substituted $Y$ from equation 17 .

Rearranging and simplifying equation 18 .

$$
(1-\gamma) k_{I}+(1+\gamma) \leq \sqrt{(1-\gamma)^{2}\left(1+k_{I}\right)^{2}+4 \gamma Z_{L}}
$$

If we square both sides:

$$
\left((1-\gamma) k_{I}+(1+\gamma)\right)^{2} \leq(1-\gamma)^{2}\left(1+k_{I}\right)^{2}+4 \gamma Z_{L}
$$

Simplifying:

$$
4 \gamma \leq 4 \gamma Z_{L}-4 \gamma k_{I}
$$

Since by assumption $1>Z_{L}$ and $k_{I} \geq 0$ then 19 is false. Thereby completing the proof.

9.3. Proof of Proposition 3. If the uninformed continues to lend, the uninformed lender will have greater rates of default than the informed lender:

$$
\Delta D \equiv E\left[D^{N}-D^{I} \mid k_{N}>0\right]>0
$$


Proof. We restrict attention to this equilibrium where the uninformed lend continues to lend (since the uninformed lend cannot have a defaults if she does not lend).

In equilibrium, the informed lender's default rate is:

$$
E\left(D^{I}\right)=\left(1-\frac{X_{H}}{1+k_{I}^{H^{*}}+k_{N}^{*}}\right)
$$

The uninformed lender's default rate is:

$$
E\left(D^{N} \mid k_{N}^{*}>0\right)=\gamma\left(1-\frac{X_{L}}{1+k_{N}^{*}}\right)+(1-\gamma)\left(1-\frac{X_{H}}{1+k_{I}^{H}+k_{N}^{*}}\right)
$$

Therefore to complete the proof we need to show that, equation 21 is greater than equation 20.

$$
\begin{aligned}
\gamma\left(1-\frac{X_{L}}{1+k_{N}^{*}}\right)+(1-\gamma)\left(1-\frac{X_{H}}{1+k_{I}^{H^{*}}+k_{N}}\right) & >\left(1-\frac{X_{H}}{1+k_{I}^{H^{*}}+k_{N}^{*}}\right) \\
\frac{X_{L}}{1+k_{N}^{*}} & <\frac{X_{H}}{1+k_{I}^{H^{*}}+k_{N}^{*}}
\end{aligned}
$$

Recalling that the informed lender must make non-negative profits, then the RHS of inequality 22 must be greater than or equal to $\frac{R}{\rho}$. From our initial assumptions $X_{L}$ must be less than equal $\frac{R}{\rho} \cdot k_{N}^{*}$ must be greater than zero. Therefore inequality 22 holds.

9.4. Proof of Proposition 4. As we reduce $X_{L}$, the expected difference between how much the informed and uniformed lender offer is increasing.

$$
\Delta \equiv(1-\gamma) k_{I}-k_{N} \text { is decreasing in } X_{L}
$$

Proof. A change in $X_{L}$ only affects the informed lender through it's effect on the uninformed lender's choice of $k_{N}$ (formally, partially differentiating the informed lender's profit maximization condition with respect to $X_{L}$ is zero).

Partially differentiating the uninformed lender's FOC condition with respect to $X_{L}$ :

$$
\gamma R \frac{1}{\left(1+k_{N}\right)^{2}}-2 \gamma R X_{L} \frac{1}{\left(1+k_{N}\right)^{3}} \frac{\partial k_{N}}{\partial X_{L}}-2(1-\gamma) R X_{H} \frac{\left(1+k_{I}^{H}\right)}{\left(k_{I}^{H}+Y\right)^{3}} \frac{\partial k_{N}}{\partial X_{L}}=0
$$

Therefore it follows:

$$
\frac{\partial k_{N}}{\partial X_{L}} \geq 0
$$

Using the proof of proposition 1, we know that the informed lender's choice of $k_{I}$ is decreasing in $k_{N}$, similarly the uninformed lender's choice of $k_{N}$ is decreasing in $k_{I}$. Consequently, 
if $X_{L}$ rises, holding $k_{I}^{H}$ constant, we know that $k_{N}$ rises, but then this itself causes $k_{I}^{H}$ to fall, which in turn causes $k_{N}$ to rise more and so on.

9.5. Proof of Corollary 1. A Perfect Bayesian equilibrium of the game is:

$$
\begin{aligned}
\text { (Informed lender) } \tilde{k}_{I}^{L} & =0, \tilde{k}_{I}^{H}=\tilde{k}_{I}^{H *}>0 \\
\left(\text { Uninformed lender) } k_{N}\right. & =k_{N}^{*} \geq 0 \\
\text { (Firm) } s_{f}^{i} & =(\text { Acc, Acc })
\end{aligned}
$$

Proof. To be completed

The proof is very similar to proposition 1 .

9.6. Proof of Proposition 5. As the informed lender's signal of the borrower improves, the difference in expected lending increases. Formally:

$$
\tilde{\Delta} \equiv[(1-q) \gamma+q(1-\gamma)] \tilde{k}_{I}-k_{N} \text { is increasing in } q
$$

Proof. To be completed

The proof is very similar to proposition 4 . 
Figure 20. Credit Worthiness Report from 2004

No.BSD/SU-62/201/20040908123203

Date $08 / 09 / 2004$

REPORT REQUESTED BY:

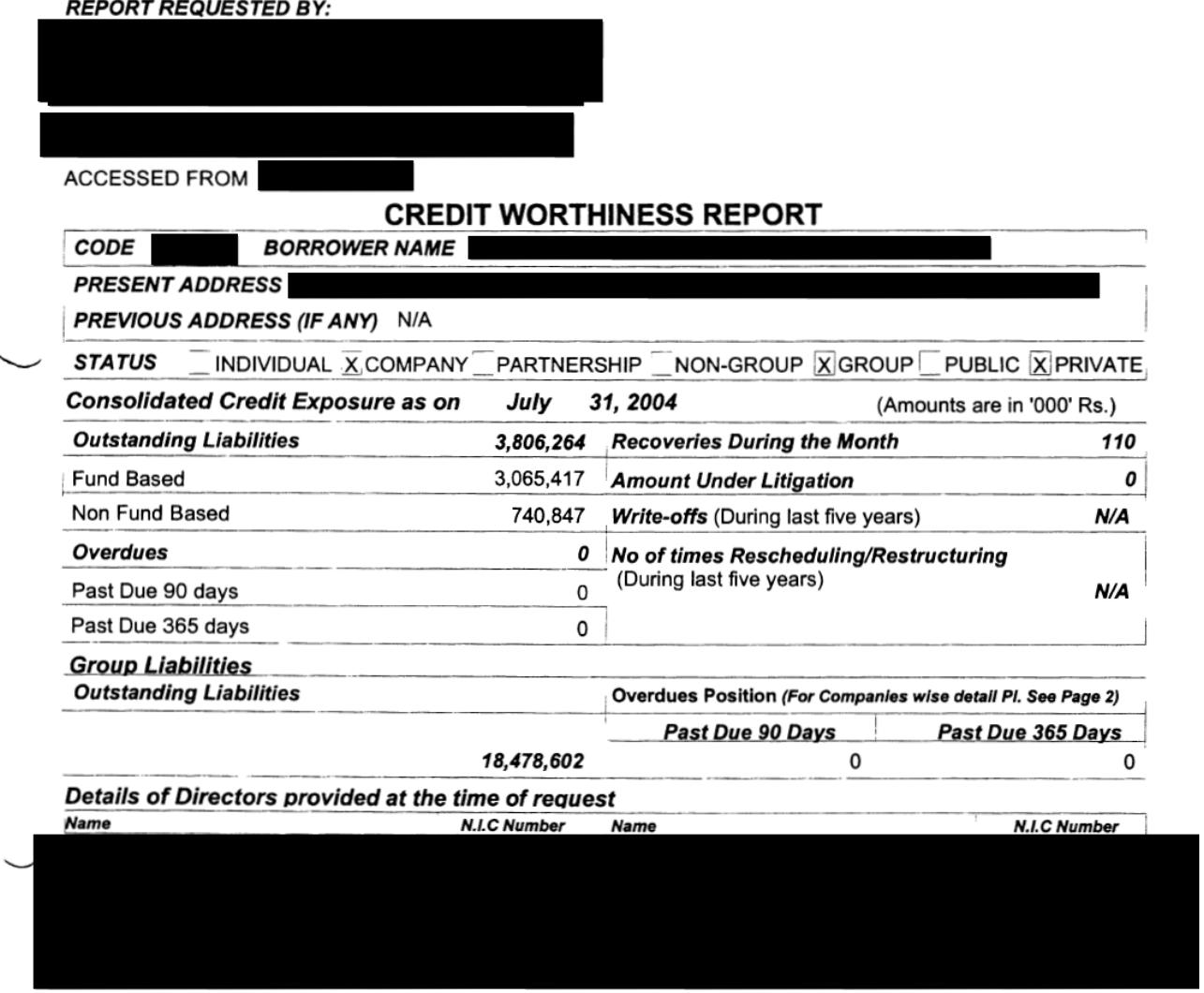

Remarks

Note: This report is generated on the basis of data provided by the financial institutions of Pakistan and input provided at the time of request.

Page $1 / 1$

A copy of the information provided by the SBP about a prospective borrower in 2004 
Figure 21. Credit Worthiness Report from 2012

STATE BANK OF PAKISTAN
CONSUMER PROTECTION DEPARTMENT
Corporate Credit Information Report

\begin{tabular}{|l|l|}
\hline \multicolumn{2}{|c|}{ Credit Enquiries } \\
\hline Enquiring Financial Institute & Enquiry Date \\
\hline \hline PRIVATE SECTOR COMMERCIAL BANK & $22 / 11 / 12$ \\
\hline PRIVATE SECTOR COMMERCIAL BANK & $28 / 08 / 12$ \\
\hline PRIVATE SECTOR COMMERCIAL BANK & $31 / 05 / 12$ \\
\hline PRIVATE SECTOR COMMERCIAL BANK & $28 / 02 / 12$ \\
\hline PRIVATE SECTOR COMMERCIAL BANK & $02 / 12 / 11$ \\
\hline
\end{tabular}

\begin{tabular}{|l|}
\hline Remarks \\
\hline \\
\end{tabular}

Disclaimer:

The Information contained in this report has been compiled from the data provided by the finacial institutions and does not represent the opinion of State Bank of Pakistan as to credit worthiness of the subject. Hence State Bank of Pakistan cannot assure any liability to the accuracy or completeness of the information. The information contained in this report is supplied on a confidential basis to you and shall not be disclosed to any other person

A copy of the information provided by the SBP about a prospective borrower in 2012. 
The Presidents/Chief Executives

May 29, 2004

\section{All Banks/ DFIs/NBFCs}

Dear Sirs/Madam,

\section{GROUP LIABILITIES IN THE CIB REPORTS}

The definition of "Group" for the purpose of CIB report as notified vide Circular No. SBP/CIB-23/94 dated August 22, 1994 has been reviewed. It has been decided that in the CIB report, the grouping of borrowers shall now be done on the basis of following criteria:

a) The names of the "Group" companies shall be reported by the financial institutions according to the definition of "Group" as contained in Definition No. 14 of the Prudential Regulations (PRs) for Corporate /Commercial Banking. Thus, the onus for correct formation of the group as per definition given in the Prudential Regulations will be on Banks/DFIs/NBFCs.

b) Banks/DFIs/NBFCs will ensure that while determining the group relationships in terms of criteria prescribed in the PRs, they should not consider the foreign national directors, directors of companies under liquidation, and nominee directors of the followingentities/agencies:

Foreign Controlled Entities.

- Banks/DFIs.

- Public Sector Enterprises.

- Federal/Provincial Government.

- Private Sector Enterprises' nominee directors on the Board of Public Sector Enterprises.

c) The definition of the Group as contained in PRs shall, however, be not applicable in the context of Government owned / controlled entities notwithstanding the fact these are listed or unlisted.

2) Since reflection of negative information in the credit report of any party adversely impacts its relationships with its lending institutions, therefore, Banks/DFIs/NBFCs are advised to be very careful while reporting the names of group entities in the CIB data. In case any party disputes the group relationship, the reporting Bank/DFI/NBFC should be able to defend its position with documentary evidence.

3) The above changes in the grouping criteria of companies have necessitated collection of certain additional data from the financial institutions. Therefore, existing formats of CIB data collection (viz. CIB-I, II and III) circulated vide BSD Circular No.4 dated 25th February, 2003 have been revised. The revised formats for CIB I, II and III are enclosed 
as Annexure-I. Banks/DFIs/NBFCs are advised to start collecting the additional information called for in the above formats from their clients and form the groups as per definition of the "Group" given in Prudential Regulations. The SBP will start collecting the monthly CIB data on the revised formats after revising its data capturing software application, for which banks/DFIs/NBFCs will be advised in due course.

Please acknowledge receipt.

Yours faitfully

(Jameel Ahmad)

Director 